EDITADO POR PATRICK LOVE Y JULIA STOCKDALE-OTÁROLA
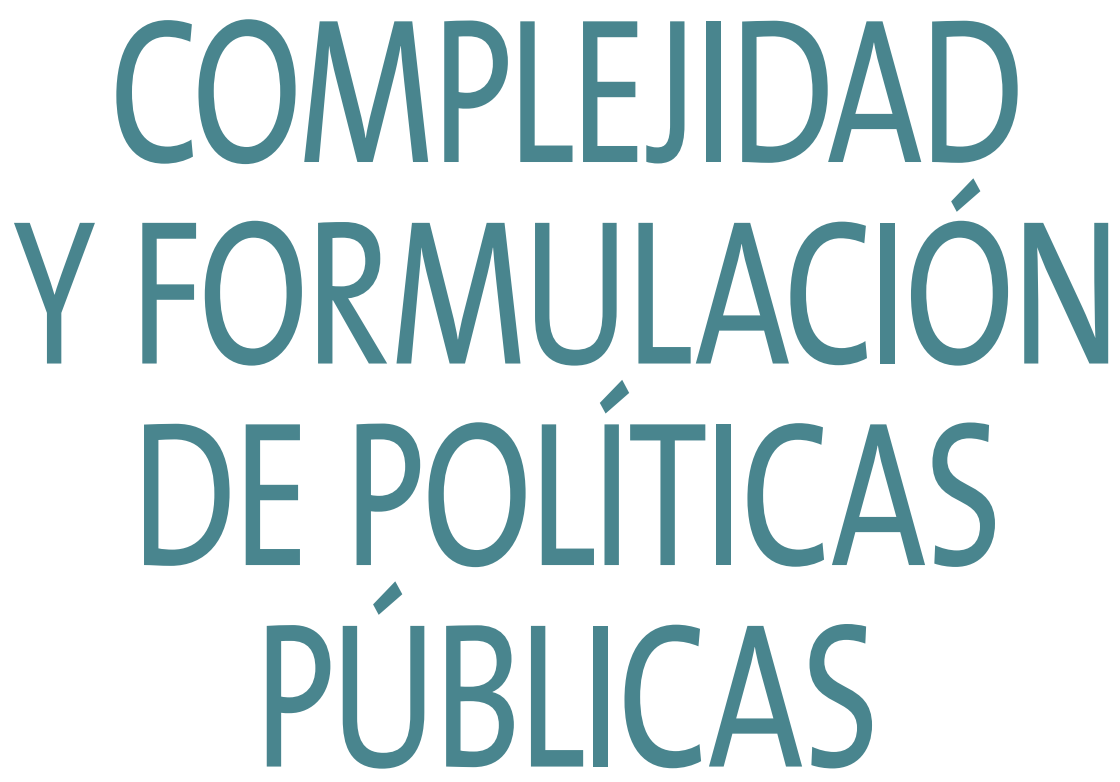

Análisis de temas de actualidad 


\section{Complejidad y formulación de políticas públicas}




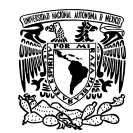

UNIVERSIDAD NACIONAL AUTÓNOMA DE MÉXICO

Dr. Enrique Luis Graue Wiechers

Rector

Dr. Leonardo Lomelí Vanegas

Secretario General

Dr. Luis Agustín Álvarez Icaza Longoria

Secretario Administrativo

Dra. Guadalupe Valencia García

Coordinadora de Humanidades

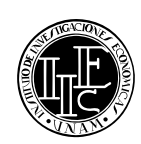

INSTITUTO DE INVESTIGACIONES ECONÓMICAS

Dr. Armando Sánchez Vargas

Director

Dra. Isalia Nava Bolaños

Secretaria Académica

Ing. Patricia Llanas Oliva

Secretaria Técnica

Mtra. Graciela Reynoso Rivas

Jefa del Departamento de Ediciones 


\title{
Complejidad y formulación de políticas públicas
}

\author{
Análisis de temas de actualidad
}

Editado por Patrick Love y Julia Stockdale-Otárola
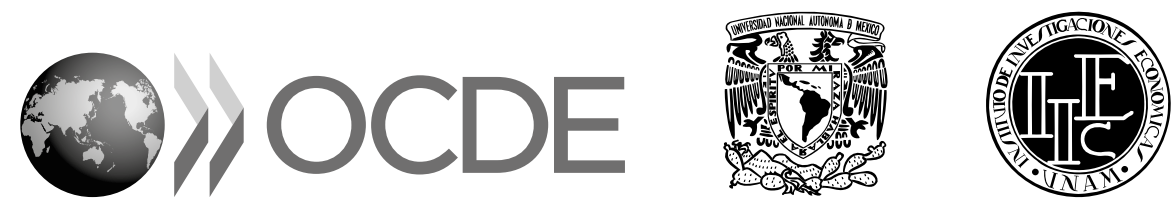
Este trabajo se publica bajo la responsabilidad del Secretario General de la OCDE. Las opiniones e interpretaciones que figuran en esta publicación no reflejan necesariamente el parecer oficial de la OCDE o de los gobiernos de sus países miembros.

Tanto este documento, así como cualquier dato y cualquier mapa que se incluyan en él no conllevan perjuicio alguno respecto al estatus o la soberanía de cualquier territorio, a la delimitación de las fronteras y límites internacionales, ni al nombre de cualquier territorio, ciudad o área.

Publicada originalmente por la OECD en inglés bajo el título:

Debate the Issues: Complexity and Policy making, OECD Insights @ 2017 OECD

๑) 2020 Universidad Nacional Autónoma de México (UNAM) para la traducción al español. Publicada por acuerdo con la OCDE, París.

La calidad de la traducción al español y su coherencia con el texto original son responsabilidad de la UNAM.

(c) 2020 OCDE para esta edición en español.

OCDE

ISBN 978-92-64-82740-0 (impresa)

ISBN 978-92-64-69725-6 (PDF)

Colección: Esenciales OCDE

ISSN 2225-8876 (en línea)
UNAM

ISBN 978-607-30-3547-7 (impresa)

ISBN 978-607-30-3548-4 (PDF)

Traducción: Gilda Moreno Manzur

Revisión académica: Doctor Alonso Aguilar Ibarra, Instituto de Investigaciones Económicas, UNAM

Coordinación editorial: Centro de la OCDE en México para América Latina e Instituto de Investigaciones Económicas, UNAM

Cuidado editorial: Ing. Laura Milena Valencia E., por el Centro de la OCDE en México para América Latina

Diagramación: D. G. Juan Carlos González Juárez

Las erratas de las publicaciones de la OCDE se encuentran en línea en: www.oecd.org/about/publishing/corrigenda.htm.

La OCDE no garantiza la exacta precisión de esta traducción y no se hace de ninguna manera responsable de cualquier consecuencia por su uso o interpretación.

El uso del contenido del presente trabajo, tanto en formato digital como impreso, se rige por los términos y condiciones que se encuentran disponibles en: http://www.oecd.org/termsandconditions. 


\section{Presentación}

\section{E}

senciales OCDE es una colección derivada de la colaboración entre el Instituto de Investigaciones Económicas (IIEc) de la UNAM y la Organización para la Cooperación y el Desarrollo Económicos (OCDE) para publicar en español los textos de la colección Insights que edita en inglés esta Organización. Las traducciones están respaldadas por la revisión académica de investigadores del Instituto expertos en los temas analizados.

El propósito de la colección es crear un espacio para el análisis de los temas sociales y económicos emergentes, con la publicación de trabajos sólidos y rigurosos que se caracterizan por su estilo claro y ágil, que facilita la lectura y acerca el conocimiento sobre el acontecer del mundo real a diversos actores no especializados en los temas.

Complejidad y formulación de políticas públicas. Análisis de temas de actualidad expone los retos que enfrenta una política pública en su fase de construcción. William Hynes menciona que considerar nuevas ciencias y enfoques de pensamiento favorecería una mejor aplicación de las políticas y, por tanto, una mejor vida para las personas.

Se argumenta también que enfrentar los desafíos presentes con nuevas técnicas, herramientas y datos de apoyo, sería de gran utilidad. Los autores destacan que durante la planeación de políticas no se debe focalizar toda la atención en un solo elemento, como el crecimiento económico, sino también en la competitividad, el bienestar de las 
personas y la desigualdad de ingresos y oportunidades. Inclusive es importante tener en cuenta nuevas problemáticas como el cambio climático, la inmigración y la pobreza.

Se debe desarrollar un enfoque nuevo capaz de comprender un contexto más amplio para explicar la economía de la sociedad actual. Lo anterior con la finalidad de desarrollar soluciones adaptativas y regulaciones que generen un cambio positivo, prestando mayor atención a todos los elementos que componen a una sociedad cada vez más compleja. Por ejemplo, mercados, instituciones, consumidores, redes de comunicación, etcétera.

Les extiendo una cordial invitación a revisar la obra Complejidad y formulación de políticas públicas. Análisis de temas de actualidad que, sin duda llevará al lector a reflexionar sobre la importancia de la construcción de políticas públicas en el entorno social y económico actual. Agradezco el trabajo de coedición de ambas instituciones, así como el esfuerzo del doctor Alonso Aguilar Ibarra, investigador del Instituto, quien llevó a cabo la revisión académica.

ARMANDO SÁNCHEZ VARGAS

Director del Instituto de Investigaciones Económicas

UNAM 


\title{
Prefacio
}

\author{
por \\ Gabriela Ramos, Directora de Gabinete de la OCDE y Sherpa ante el G20
}

\section{L}

a OCDE está orgullosa del importante papel que ha desempeñado en reconciliar la economía con la naturaleza y con la sociedad. En la actualidad, la comunidad mundial no logra captar del todo esta agenda fundamental y avanzar en ella. Para hacerlo necesitamos mejorar nuestros marcos analíticos, herramientas de políticas públicas y modelos.

Hace casi 10 años, la Crisis Financiera fue una llamada de alerta sobre las deficiencias de nuestros enfoques de política. Pero varias otras tendencias relevantes también se desplazaban en la dirección equivocada. Tal vez la acusación más grave contra nuestros enfoques económicos haya sido el intento por parte de la comunidad internacional de tomar medidas serias en relación con el cambio climático, y no haberlo logrado. Un problema vinculado con esto es el insostenible consumo de los recursos de la Tierra que en la actualidad se encuentra en 1.6 planetas, es decir, la Tierra tarda un año y siete meses en regenerar lo que utilizamos en un año.

La desigualdad en muchos países de la OCDE también ha aumentado de manera constante $\mathrm{y}$ ha llegado ahora a niveles críticos, lo que debilita la cohesión social y la confianza, y a la vez, el crecimiento y el bienestar. La procuración ilimitada de un mayor crecimiento y consumo, el tratamiento tradicional de la degradación ambiental y la desigualdad de ingresos como externalidades o las fallas de mercado y el supuesto de que las personas se organizarán con sus propios medios en un estado socialmente deseable, han 
sido parte del problema. Simplemente mejorar la manera como los mercados operan no resolverá nuestros apremiantes problemas. Alan Kirman sostiene que el paradigma actual no es validado por la evidencia empírica ni tampoco tiene fundamentos teóricos sólidos.

Los economistas y los responsables de formular políticas públicas no han logrado apreciar la complejidad de la conducta humana y los sistemas en los que vivimos. Un enfoque de complejidad nos permite observar los sistemas de sistemas, que consisten en enormes números de elementos individuales que interactúan en formas complicadas, como los ecosistemas, los mercados financieros y las redes de energía, o fenómenos sociales como la urbanización y la migración.

También cuestiona el pensamiento predominante sobre temas clave. Por ejemplo, de acuerdo con la curva de Kuznets, la desigualdad de ingresos deberá subir primero y después bajar, a medida que el ingreso de los países cambia de bajo a alto. Sin embargo, la evidencia empírica no parece confirmar este concepto. En este libro, un enfoque basado en la complejidad económica por César Hidalgo y otros sugiere que la desigualdad depende no solo de la tasa o la etapa de crecimiento de un país, sino también de su tipo de crecimiento y sus instituciones.

En economía, aún hablamos de flujos, masas, equilibrio, entre otros términos (por ejemplo, un modelo de gravedad del comercio). Pero estos términos están arraigados en la física clásica, desarrollada antes de la teoría de la relatividad y la cuántica. Las nuevas ciencias de la complejidad pueden proporcionar perspectivas sobre cómo los grupos de personas se comportan realmente cuando actúan o reaccionan en conjunto para formar sistemas económicos y sociopolíticos. Dichos sistemas no operan sencillamente como series de acciones y reacciones, sino con retroalimentación, no-linealidad, puntos de inflexión, singularidades, emergencia y todas las demás características de los sistemas complejos.

Inspirado por la iniciativa Nuevos Enfoques ante los Retos Económicos (NAEC, por sus siglas en inglés), en este libro Complejidad y formulación de políticas públicas. Análisis de temas de actualidad, se presentan detalles de los nuevos marcos que mejor reflejan las 
complejidades de las economías y sociedades modernas. Nuestras economías no son sistemas cerrados de equilibrio general; son complejas y adaptativas, incorporadas en sociedades específicas con su historia, su cultura y sus valores propios, así como en los entornos naturales regidos por las leyes de la biofísica.

Diversos y prominentes economistas se han unido a este llamado a un nuevo enfoque a la formulación de políticas. Andy Haldane, Economista en Jefe del Banco de Inglaterra, escribe que la NAEC y la disposición de la OCDE a considerar un enfoque de complejidad "coloca a la Organización a la vanguardia de la labor de impulsar el análisis económico y la formulación de políticas hacia el siglo XXI". Por su parte, Eric Beinhocker, del Institute for New Economic Thinking, expresa la esperanza de que "la OCDE seguirá desempeñando una función de liderazgo, por medio de la NAEC y sus otras iniciativas, en el nuevo pensamiento económico, no solo en un estrecho sentido técnico, sino también en el sentido amplio de ayudar a forjar una nueva visión que devuelva a las personas al centro de nuestra economía".

Después de haber dirigido las iniciativas NAEC y Crecimiento Incluyente, he impulsado en la OCDE, en los países miembros y en los países asociados clave, así como en el G20, la idea de que el crecimiento económico es un medio para llegar a un fin y no un fin en sí mismo. En este libro de la colección Esenciales se plantea que nuestros esfuerzos para entender el crecimiento económico como un medio para mejorar el bienestar podrían beneficiarse de un enfoque que considera al crecimiento incluyente como el resultado de interacciones complejas entre la economía, la política, la psicología, la cultura, la historia, el medio ambiente y la ambición.

Si queremos que el crecimiento sea incluyente, nuestra manera de pensar tiene que ser incluyente también. 



\section{Índice}

Introducción: Un enfoque de complejidad a los retos económicos por William Hynes $\ldots \ldots \ldots \ldots \ldots \ldots \ldots \ldots \ldots \ldots \ldots$

\section{Complejidad y formulación de políticas}

Dejemos de pretender que es posible controlar una economía por Angel Gurría . . . . . . . . . . . . . . . . . . . . . . . . 18

No es solamente la economía: la sociedad también

es un sistema complejo

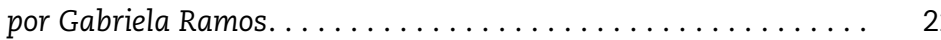

¿Un nuevo papel para la ciencia en la formación de políticas en la era de la complejidad?

por Vladimir Šucha $\ldots \ldots \ldots \ldots \ldots \ldots \ldots \ldots \ldots \ldots . \ldots \ldots$

Hormigas, algoritmos y complejidad sin gestión

por Deborah M. Gordon. ...................... $\quad 30$

Sortear problemas perversos

por Julia Stockdale-Otárola .......................... 34

Fuera de la complejidad, ¿una tercera vía?

por Bill Below ................................ 37

Complejidad y economía

Complejidad y política económica

por Alan Kirman . . . . . . . . . . . . . . . . . . . . . . 42

Un holista pragmático: Herbert Simon, economía

y la arquitectura de la complejidad

por Vela Velupillai ......................... 45

De la crisis económica a la crisis en economía

por Andy Haldane . . . . . . . . . . . . . . . . . . . . . . . . 49

Teoría de la complejidad y economía evolutiva por Robert D. Atkinson . . . . . . . . . . . . . . . . . . . 53

Complejidad, modestia y política económica por Lex Hoogduin $\ldots \ldots \ldots \ldots \ldots \ldots \ldots \ldots \ldots \ldots \ldots$

La creciente complejidad de la economía global por Sony Kapoor . . . . . . . . . . . . . . . . . . . . . . . 
Complejidad económica, instituciones y desigualdad de ingresos

por César Hidalgo y Dominik Hartmann

Multitudes, consensos y complejidad en el pronóstico económico

por Brian Dowd...

\section{Complejidad y sistema financiero}

Un sistema financiero global complejo por Adrian Blundell-Wignall .................... 74

La complejidad y una mejor regulación financiera por Harald Stieber. . . . . . . . . . . . . . . . . . . . . . 78

Modelos basados en agentes para contribuir a un mejor funcionamiento de la economía por Richard Bookstaber..........................

\section{Aplicaciones de la teoría de la complejidad}

Urbanización y sistemas complejos por Colin Harrison. . . . . . . . . . . . . . . . . . . . . . . . .

Macrodatos, teoría de la complejidad y desarrollo urbano por Ricardo Herranz . . . . . . . . . . . . . . . . . . . . . . .

Innovación y complejidad por Andrew Wyckoff . . . . . . . . . . . . . . . . . . . . . 96

Gobernanza de la educación en un mundo complejo por Tracey Burns ...

El desarrollo como resultado de un sistema adaptativo complejo por Frans Lammersen y Jorge Moreira da Silva ..

\section{Hacia una nueva narrativa}

Cantar para nuestro tiempo también, o lo que Homero puede enseñarnos sobre la complejidad por Patrick Love. . . . . . . . . . . . . . . . . . . . . . . . 108

Una nueva narrativa para una era compleja por Eric Beinhocker

Decir toda la verdad en un entorno de posverdad por Gabriela Ramos. 


\title{
Introducción: \\ Un enfoque de complejidad a los retos económicos
}

\author{
por \\ William Hynes, Iniciativa Nuevos Enfoques \\ ante los Retos Económicos (NAEC) de la OCDE
}

En 2012 la OCDE puso en marcha su iniciativa Nuevos Enfoques ante los Retos Económicos (NAEC) para reflexionar sobre las enseñanzas para el análisis económico y la formulación de políticas públicas obtenidas de la crisis financiera y la Gran Recesión. El Gobernador del Banco Central Europeo, Jean-Claude Trichet, dijo lo siguiente: "Como formulador de políticas durante la crisis, encontré que los modelos disponibles brindan una ayuda limitada. De hecho, iría más allá: ante la crisis, nos sentimos abandonados por las herramientas convencionales". Pero incluso antes de la crisis, Greg Mankiw, de la Universidad de Harvard, lamentó que "la investigación macroeconómica de las últimas tres décadas haya tenido un impacto menor en el análisis práctico de la política monetaria o fiscal".

La iniciativa NAEC examinó las deficiencias de los modelos analíticos y promueve nuevas herramientas y datos de políticas. Cuestiona las ideas y los métodos tradicionales y desafía los enfoques de pensamiento grupal y de silo al solicitar comentarios y críticas desde fuera de la Organización, así como aportes de las ciencias sociales, como la sociología, la psicología y la historia, para enriquecer los debates sobre políticas.

Si bien la crisis financiera golpeó el núcleo de la teoría y los modelos económicos tradicionales, en 2016 se hizo evidente que el 
fracaso del pensamiento y las acciones económicos era mucho más profundo y más desestabilizador de lo que pensábamos, por lo que parte del mandato de la NAEC es desarrollar una agenda para un crecimiento incluyente y sostenible.

Lo anterior resulta aún más urgente dados el rechazo violento a la globalización, el aumento de las desigualdades de ingresos y oportunidades, y el impacto negativo del crecimiento sobre el medio ambiente. Necesitamos desarrollar lo que Eric Beinhocker llama una "nueva narrativa de crecimiento", que coloque a las personas en el centro de la política económica. Por tanto, la NAEC está ayudando a centrarse en la redistribución, un concepto descuidado en el análisis económico durante muchos años, y ayuda a garantizar que las decisiones de política mejoren la vida de las personas que se encuentran en la parte inferior de la distribución del ingreso.

También ayuda a considerar el bienestar de las personas como un concepto multidimensional, lo que implica reconsiderar elementos importantes de la narrativa económica, como la justicia y la cohesión social. La NAEC lo hace pensando de una nueva manera, haciendo hincapié en la necesidad de empoderar a las personas, las regiones y las empresas para que desarrollen todo su potencial. Este es el elemento central del Nexo Productividad-Inclusión que considera cómo expandir los activos productivos de una economía al invertir en las competencias de sus ciudadanos, y eso proporciona condiciones iguales para que las empresas compitan, incluso en regiones rezagadas.

Sin embargo, los retos son demasiado complejos e interconectados para los modelos y análisis convencionales. Como afirma Andy Haldane, la economía global se caracteriza cada vez más por interrupciones, puntos de inflexión, equilibrios múltiples, incertidumbres radicales y las demás características de los sistemas complejos. Es por eso que un tema clave de la NAEC ha sido la complejidad y la interconexión de la economía, ejemplificada por el Nexo Productividad-Inclusión.

Los colaboradores de esta colección sostienen que la complejidad y el pensamiento sistémico pueden mejorar la comprensión de temas como las crisis financieras, la sostenibilidad del crecimiento, la 
competitividad, la innovación y la planificación urbana. Reconocer la complejidad de la economía implica que se debe prestar mayor atención a las interacciones, las consecuencias no deseadas, la estabilidad, la resiliencia, los amortiguadores de políticas y las salvaguardas.

En un trabajo conjunto con la Comisión Europea y el Institute for New Economic Thinking (Instituto para el Nuevo Pensamiento Económico) (INET) Oxford, la iniciativa NAEC demostró en una serie de talleres que la economía de la complejidad es un enfoque prometedor para brindar nuevas ideas sobre los principales retos de las políticas públicas y una emocionante agenda de investigación en el futuro.

Los talleres ofrecieron una oportunidad en el momento preciso para que los responsables de formular políticas públicas, académicos e investigadores analizaran las aplicaciones de políticas que surgen del estudio de la complejidad. En la Mesa Redonda de la NAEC celebrada en diciembre de 2016 se analizó si la economía estaba cerca de un punto de inflexión: una transición a un nuevo paradigma de complejidad conductual. Hay un amplio acuerdo entre los economistas sobre las limitaciones y las deficiencias del paradigma de expectativas racionales y mucha controversia sobre cómo avanzar.

La primera etapa del trabajo de complejidad de la NAEC ha abogado por un examen más profundo de la complejidad. En el futuro, será importante demostrar el valor de la complejidad, el pensamiento sistémico y los modelos basados en agentes en una serie de áreas, incluidas las redes financieras, los sistemas urbanos y los demás temas destacados en esta colección. El desafío es demostrar el valor del enfoque.

La complejidad ofrece la oportunidad de abordar inquietudes de larga data acerca de los supuestos, teorías y modelos económicos. Para la OCDE, también ofrece el potencial de crear mejores políticas para una vida mejor.

\section{Enlaces útiles}

El artículo original sobre Esenciales OCDE, incluidos enlaces y material complementario, puede consultarse en: $h t t p: / / w p . m e / p 2 v 60 D-2 \mathrm{Pl}$

Consulte la serie completa en: http://oecdinsights.org/?s=NAEC+complexity 



\section{Complejidad y formulación de políticas}




\section{Dejemos de pretender que es posible controlar una economía}

por Angel Gurría, Secretario General de la OCDE

La crisis expuso algunas fallas graves en nuestro pensamiento económico. Demostró la necesidad de considerar la política económica con enfoques más críticos y novedosos. También reveló las limitaciones de las herramientas existentes para el análisis estructural al tener en cuenta los vínculos clave, la retroalimentación y las concesiones mutuas, por ejemplo, entre el crecimiento, la desigualdad y el medio ambiente.

Deberíamos aprovechar la oportunidad para desarrollar una nueva comprensión de la economía como un sistema altamente complejo que, al igual que cualquier sistema complejo, se reconfigura constantemente para responder a múltiples aportes e influencias, a menudo con consecuencias imprevistas o indeseables. Eso tiene muchas implicaciones. Sugiere que los responsables de formular políticas deberían estar constantemente alerta y ser más humildes respecto a sus recomendaciones sobre políticas, actuar más como navegadores que como mecánicos, y estar abiertos a riesgos sistémicos, efectos secundarios, fortalezas, debilidades y sensibilidades humanas. Esto exige un cambio en nuestra mentalidad y en nuestros libros de texto. Como dijo John Kenneth Galbraith alguna vez, "La visión convencional sirve para protegernos del doloroso trabajo de pensar".

Por tal razón en la OCDE lanzamos una iniciativa llamada Nuevos Enfoques ante los Retos Económicos (NAEC). Con ella queremos entender mejor cómo funciona la economía, en toda su complejidad, y diseñar políticas que reflejen esta comprensión. Nuestro objetivo es considerar y abordar las consecuencias no intencionales de las políticas y a la vez desarrollar nuevos enfoques que fomenten un crecimiento más sostenible e incluyente.

La complejidad es una característica común de un número creciente de problemas de política pública en un mundo cada vez más globalizado que emplea tecnologías sofisticadas y encara limitaciones de recursos. 
El informe del Foro Global de Ciencias de la OCDE (2009) sobre Aplicaciones de la Ciencia de Complejidad para Políticas Públicas nos recuerda la distinción entre los sistemas complicados y complejos. La ciencia tradicional (y la tecnología) sobresalen en lo complicado, pero todavía están en una etapa temprana de entendimiento de fenómenos complejos como el clima.

Por ejemplo, el automóvil complicado se puede entender bien utilizando análisis de ingeniería normales. Por el contrario, un conjunto de automóviles que viajan por una carretera, es un sistema complejo. Los conductores interactúan y ajustan mutuamente su comportamiento en función a diversos factores, como percepciones, expectativas, hábitos e incluso emociones. Para comprender el tránsito y construir mejores autopistas, establecer límites de velocidad, instalar sistemas automáticos de radar, entre otros, es útil contar con herramientas que puedan ajustarse a patrones de comportamiento no lineales y colectivos, y a una variedad de tipos de conductores o reglas que podrían imponerse. En este caso se necesitan las herramientas de la ciencia de la complejidad. Y necesitamos mejores reglas de circulación en varias áreas.

No se trata de un debate académico. La importancia de la complejidad no se limita a este ámbito. Tiene algunos defensores poderosos en el mundo de la política. Andy Haldane, del Banco de Inglaterra, pensó que el sistema financiero global es un sistema complejo y se centró en aplicar las lecciones de otras disciplinas de la red, como la ecología, la epidemiología y la ingeniería, a la esfera financiera. En términos más generales, está claro que el lenguaje de la teoría de la complejidad (puntos de inflexión, retroalimentación, interrupciones, colas gruesas) ha entrado a formar parte del léxico financiero y regulatorio. Haldane demostró el valor de adoptar una lente de complejidad, proporcionando información sobre las vulnerabilidades estructurales que se acumularon en el sistema financiero. Esto ha llevado a sugerencias de políticas para mejorar la solidez del sistema financiero.

Más cerca de casa, Bill White, presidente de nuestro Comité de Revisión Económica y de Desarrollo (EDRC) ha defendido fervientemente el pensar en la economía como un sistema complejo. Ha hablado en numerosas reuniones de la OCDE, en parte en términos 
de explicación y en parte a manera de advertencia, acerca de que los sistemas crecen como resultado de procesos acumulativos, pueden tener dinámicas altamente impredecibles y pueden demostrar una no-linealidad significativa. Como resultado, Bill ha instado a los responsables de formular políticas a aceptar más incertidumbre y ser más prudentes. También instó a los economistas a aprender algunas lecciones extremadamente sencillas pero importantes de aquellos que han estudiado o trabajan con sistemas complejos como biólogos, botánicos, antropólogos, controladores de tráfico y estrategas militares.

Quizás la perspectiva más importante de la complejidad es que los responsables de formular políticas públicas deberían dejar de pretender que una economía puede controlarse. Los sistemas son propensos a comportamientos sorprendentes, a gran escala y aparentemente incontrolables. Por el contrario, se debe hacer mayor hincapié en aumentar la capacidad de resiliencia, fortalecer los amortiguadores de políticas y promover la adaptabilidad fomentando una cultura de experimentación de políticas.

En la OCDE, estamos comenzando a aceptar la complejidad. Durante varios años, hemos estado mapeando el "genoma" del comercio con nuestra base de datos Trade in Value Added (TiVA) para explicar las interconexiones comerciales entre países.

Hemos examinado las posibilidades de acoplar modelos de sistemas económicos y de otro tipo, por ejemplo, ambientales (climáticos) y sociales (desigualdad). Nuestro trabajo sobre Costos de la Inacción y Limitaciones de Recursos: Implicaciones para el Crecimiento a Largo Plazo (CIRCLE) es un ejemplo clave de la vinculación de modelos biofísicos y modelos económicos para medir el impacto de la degradación ambiental y el cambio climático en la economía.

También buscamos gobernar sistemas complejos en áreas tan diversas como la educación y la política comercial internacional. Y estamos analizando el potencial para aprovechar los macrodatos, un elemento indispensable de los enfoques de modelaje de complejidad. Pero queda mucho por hacer para enriquecer completamente nuestro trabajo con las perspectivas de la complejidad. 
A la OCDE le complace trabajar con socios fuertes: el Instituto para el Nuevo Pensamiento Económico (INET) de Oxford y la Comisión Europea, para ayudar a los responsables de formular políticas públicas a avanzar en el uso del pensamiento sistémico complejo para abordar algunos de los retos más difíciles.

Queda una cuestión importante. ¿Cómo se pueden aplicar las ideas y los métodos de la ciencia de la complejidad para ayudar a los responsables de formular políticas públicas a medida que abordan problemas difíciles en áreas como protección ambiental, regulación financiera, sostenibilidad o desarrollo urbano?

El Taller sobre Complejidad y Política realizado en septiembre de 2016 en la OCDE ayudó a encontrar la respuesta: estimular un nuevo pensamiento, nuevos enfoques de políticas y, en última instancia, mejores políticas para una vida mejor.

\section{Enlaces útiles}

El artículo original sobre Esenciales OCDE, incluidos enlaces y material complementario, puede consultarse en: http://wp.me/p2v6oD-2Dz Consulte la serie completa en: http://oecdinsights.org/?s=NAEC+complexity 


\section{No es solamente la economía: la sociedad también es un sistema complejo}

por Gabriela Ramos, Directora de Gabinete de la OCDE y Sherpa ante el G20

La desigualdad de ingresos y riqueza no es un fenómeno nuevo. Por el contrario, parece que es una característica permanente en la historia humana, y con los años, sus causas y consecuencias se han vuelto más numerosas e interconectadas. Lo mismo es cierto para muchos fenómenos sociales, y aunque el mundo parece más complicado hoy, no lo es. Lo que es diferente es el mayor número de ámbitos en los que se espera que las políticas públicas incidan. Respecto a las desigualdades de ingresos y riqueza, los gobiernos tienen que tomar decisiones sobre varias áreas interrelacionadas, como los impuestos, la educación o la salud.

Desafortunadamente, las herramientas a disposición de los responsables de formular políticas públicas no siempre se han actualizado lo suficientemente rápido como para hacer frente a estos retos y sus interrelaciones. Además, las políticas a menudo se diseñan dentro de los estrechos límites de un tema, sin tomar en cuenta sus consecuencias en otros.

Los economistas han intentado simplificar y abstraerse de la realidad con supuestos limitantes como el agente representativo y el equilibrio general. También han dado prioridad al objetivo de la eficiencia, en detrimento de otras consideraciones importantes, como la equidad. Sin embargo, el uso de datos agregados oscurece las consecuencias distributivas de las políticas: una economía en su conjunto puede estar funcionando bien, pero, como hemos visto en los últimos años, hay graves consecuencias para la cohesión social $\mathrm{y}$, en última instancia, para el propio crecimiento, si se excluye a los grupos grandes de los beneficios de la prosperidad económica. Al definir las políticas de crecimiento que apuntaban solo a aumentar el PIB per cápita, se prestó una atención inadecuada a las instituciones, el comportamiento humano y la cultura. Estos enfoques fallaron al no tomar en cuenta adecuadamente las realidades de los mercados, las decisiones de los consumidores y la interconexión de las redes económicas, de comunicación y sociales. 
En marcado contraste con los supuestos de la economía neoclásica, los sistemas socioeconómicos no son estables, sino que están en constante cambio. La ciencia de la complejidad genera nuevas ideas y nos proporciona las herramientas e instrumentos analíticos para ayudarnos, como individuos y sociedades, a lidiar con este nuevo entendimiento de la economía. Aborda algunas de las limitaciones que restringen a la economía convencional y, en última instancia, nos ayuda a asesorar mejor a gobiernos e instituciones públicas.

Por ejemplo, adoptando un enfoque basado en la complejidad podemos comenzar a reconocer que las causas y las consecuencias de la desigualdad y los principales problemas económicos y sociales están entrelazados. Además de contribuir sustancialmente al aumento de la desigualdad de riqueza, la financiarización de la economía también condujo a un aumento de los riesgos sistémicos, donde un problema en los mercados de alto riesgo desencadenó una gran crisis económica que ha puesto obstáculos adicionales en el camino de los grupos más vulnerables en todo el mundo.

Al igual que el sistema financiero y sus principales riesgos, nuestros sistemas sociales son complejos y vulnerables. Tomando en cuenta el aumento de la fragmentación y las divisiones en nuestras sociedades (y sumando el reto de la integración de los migrantes y los grupos marginados), se debe prestar más atención a la estabilidad social. En este sentido, las políticas para atender los problemas sociales no solo deberían basarse en las herramientas y medidas económicas tradicionales, sino también en ampliarlas para aportar conocimientos sobre disciplinas útiles.

Se necesita este enfoque más realista de cómo funcionan realmente las personas y la economía, una agenda integrada de crecimiento incluyente que también considere consecuencias no intencionales, concesiones mutuas y complementariedades entre los objetivos de las políticas.

De hecho, creo que los economistas -y los responsables de formular políticas a quienes asesoran- pueden mejorar escuchando y aprendiendo de los demás. No es fácil para una organización que tiene la palabra "Económico" en su nombre, pero 
necesitamos romper el monopolio de la economía sobre la política, buscando otras disciplinas como la física, la biología, la psicología, la sociología, la filosofía y la historia. Las sociedades y las economías no son características estáticas que puedan predecirse, sino sistemas evolutivos con puntos de ruptura y cambios que deben caracterizarse mejor.

En la OCDE, reconocemos el potencial del nuevo pensamiento económico, basado en la teoría de la complejidad y la economía evolutiva y conductual. Las innovaciones tecnológicas y analíticas están impulsando una revolución en las ciencias físicas, las ciencias biológicas y las ciencias sociales, rompiendo las barreras entre disciplinas y estimulando enfoques nuevos e integrados para retos apremiantes y complejos. Los avances en potencia informática están abriendo nuevas posibilidades para integrar modelos de sistemas, modelaje basado en agentes y análisis de redes. Únicamente utilizando de manera adecuada estos nuevos enfoques podemos esforzarnos por crear modelos sociales y económicos que proporcionen una representación más precisa del mundo que nos rodea. Estas herramientas también nos permiten alejarnos de las representaciones promedio, o analizar las reservas y no solo ante flujos de la economía (ingresos versus desigualdad de la riqueza).

Y, de hecho, la economía está comenzando a incorporar ideas de otras disciplinas. Por ejemplo, las expectativas pueden ser admirablemente racionales en los modelos tradicionales, pero al combinar psicología y economía estamos diseñando políticas basadas en cómo se comportan realmente las personas reales, no en suposiciones limitadas sobre cómo debería comportarse una persona promedio ficticia. Adoptando un enfoque basado en problemas, podemos diseñar políticas para influir en las personas y encauzarlas en la dirección correcta en áreas como políticas de consumo, y la regulación y la protección del medio ambiente.

La OCDE es parte de esta revolución y ya estamos transformando nuestro pensamiento y actuación en materia de política. Con la iniciativa Nuevos Enfoques ante los Retos Económicos (NAEC), estamos revisando detenidamente nuestros métodos analíticos, nuestros datos y el asesoramiento sobre políticas. 
En muchos artículos de esta serie se ha sostenido que la economía es un sistema adaptativo complejo. La sociedad también es un sistema complejo. Está formada por la interacción y la dependencia mutua de las personas, y es acorde a su comportamiento espontáneo y natural. Desde el surgimiento de las sociedades de cazadores-recolectores, la desigualdad ha amenazado con socavar y debilitar el tejido del sistema social. Si queremos superar los efectos perniciosos de estas desigualdades, debemos pensar en las interacciones entre nuestros sistemas sociales y económicos, que siguen su propia lógica, y diseñar políticas que ayuden a nuestras economías a crecer. Pero el crecimiento no es un fin en sí mismo. Tiene que ser incluyente para garantizar que todos los segmentos de nuestras sociedades prosperen.

El pensamiento sistémico puede ayudarnos a combatir la desigualdad y desarrollar una agenda para un crecimiento incluyente. A medida que extraemos las interrelaciones entre las diferentes áreas de política, comenzamos a comprender cómo interactúa el sistema económico con otros sistemas, así como con la historia, la política y las ambiciones de los países. Nuestra tarea ahora es hacer un buen uso de este creciente entendimiento para que la economía funcione mejor para todas las personas.

\section{Enlaces útiles}

El artículo original sobre Esenciales OCDE, incluidos enlaces y material complementario, puede consultarse en: $h t t p: / / w p . m e / p 2 v 60 D-2 D D$

Consulte la serie completa en: http://oecdinsights.org/?s=NAEC+complexity 


\section{¿Un nuevo papel para la ciencia en la formación de políticas en la era de la complejidad?}

por Vladimir Šucha, Director General, Comisión Europea, Centro Común de Investigación

La reciente crisis financiera fue un llamado de atención tanto para los científicos como para los responsables de formular políticas. Expuso vínculos nuevos y desconocidos entre las magnitudes económicas, pero también entre varias partes de nuestro mundo moderno y globalizado. Además, ayudó a revelar las limitaciones de algunos enfoques en economía y ciencias sociales que resultaron ser inadecuados para este nuevo mundo.

La crisis, sobre todo, mostró que la economía es una actividad altamente compleja, dinámica y en evolución, con el potencial, a veces, de producir resultados impredecibles (y a menudo no deseados). Por último, mostró la necesidad de abarcar más apropiadamente esta complejidad en el análisis de políticas subyacente de la ciencia, así como en el proceso de formulación de políticas en sí.

Entonces, ocho años después del inicio de la crisis, ¿se han desplazado los científicos y los responsables de formular políticas de su zona de confort? ¿Se están adoptando nuevas formas de pensar? ¿Se están aplicando en la práctica? ¿Qué tenemos que hacer para asegurar que generen mejores políticas y, en última instancia, en sociedades más justas y resistentes?

En su papel de servicio de ciencia y conocimientos de la Comisión Europea, se supone que el Centro Común de Investigación (JRC, por sus siglas en inglés) supuestamente cierra la brecha entre la ciencia y los responsables de formular políticas, al igual que la OCDE. Con base en nuestra experiencia, creemos que se ha avanzado mucho. Sin embargo, para que la ciencia que se ocupa de tal complejidad realice todo su potencial todavía queda mucho trabajo por hacer.

Por supuesto, la ciencia de la complejidad existe desde hace algunas décadas. Es el estudio científico de sistemas complejos, donde muchos componentes interactúan produciendo una conducta global que no podría predecirse fácilmente usando solamente 
modelos simples que se basan en la interacción ordinaria entre los elementos constitutivos individuales de dichos sistemas. Dado que tales sistemas se pueden encontrar en muchas áreas de la vida, la ciencia de la complejidad se usa en varios campos diferentes, incluyendo biología, ciencias sociales, informática, transporte, energía y protección de infraestructura crítica.

Se ha desarrollado rápidamente en las últimas décadas. Conceptos como la no-linealidad, la autoadaptación, la emergencia o surgimiento, la dinámica caótica y los equilibrios múltiples, ahora están firmemente establecidos. Se han desarrollado valiosas herramientas, como el análisis de sensibilidad, el modelaje de escenarios y la previsión, la ciencia de redes y el modelaje de sistemas dinámicos, que permiten aplicar adecuadamente dichos conceptos.

La economía tardó relativamente en adoptar estos conceptos y herramientas. Sin embargo, después de la crisis, hay mayor interés en aplicarlos, particularmente a los mercados financieros.

El Centro Común de Investigación avanza en esta dirección. Por ejemplo, nuestros investigadores emplean la ciencia de redes para estimar las interrelaciones entre el sector bancario y otros inversionistas institucionales y cómo se podrían propagar los choques dentro del sistema.

Sin embargo, nuestra impresión es que, a pesar del mayor interés de los últimos años, la economía de la complejidad aún necesita extenderse más ampliamente entre los economistas. No debe ser solo propiedad de un pequeño número de personas externas.

También creemos que todavía no es tan útil como podría ser para la formulación de políticas. Esto se debe a que sigue siendo bastante abstracta. En muchos casos, puede ayudarnos a comprender las características teóricas o la base de un fenómeno, pero aún es difícil usarla para la resolución práctica de problemas. Esto puede deberse a que los modelos relacionados no están suficientemente detallados o a que los datos utilizados no son lo suficientemente adecuados para el problema en consideración. 
Por supuesto, hay muchas fuentes nuevas de datos disponibles. La tarea es desarrollar paradigmas innovadores para su recopilación, y también nuevos métodos para su análisis, ya que grandes cantidades de datos a menudo pueden oscurecer en lugar de aclarar un problema, si no se cuenta con las técnicas apropiadas para interpretarlos y darles sentido.

Por consiguiente, los científicos necesitan desarrollar nuevos enfoques para recopilar y organizar datos, como la forma de manejar los macrodatos o bien, la minería de texto y datos. También necesitan explorar modelos y herramientas para el análisis de data en un contexto de políticas, incluyendo indicadores, visualizaciones innovadoras y métodos de evaluación de impacto.

La buena noticia es que los responsables de formular políticas ahora se están abriendo, al menos en cierta medida. La mayoría de ellos ahora se dan cuenta de que es esencial prestar atención a las interrelaciones entre las áreas de política y los objetivos relacionados, así como mejorar la evidencia sobre el movimiento simultáneo de varios objetivos y palancas de políticas.

Saben que el impacto de la regulación no puede juzgarse únicamente en función de sus logros específicos dentro de un contexto dado, sino que también puede producir consecuencias no intencionales (y no deseadas) en otras áreas fuera del contexto bajo consideración. Por consiguiente, hay una demanda potencial de un mayor uso de la ciencia de la complejidad para comprender vínculos tan amplios en sistemas complejos.

Sin embargo, puede ser difícil explicar resultados ilógicos a los políticos y a los responsables de formular políticas.

Del mismo modo, si bien los científicos deben sensibilizar a los responsables de formular políticas sobre la complejidad de los sistemas con los que se enfrentan, es importante no sobrecargarlos. Si sienten que estos sistemas son tan complejos que nadie es capaz de entenderlos o influenciar en ellos, el resultado será optar por la inercia y el derrotismo. 
Además, no tiene mucho sentido utilizar la ciencia de la complejidad para comprender los vínculos en los sistemas, a menos que los responsables de formular políticas estén preparados para luchar por soluciones integradas que trabajen entre sí a través de los silos. Todos están comprometidos a hacer esto en teoría, pero no siempre sucede en la práctica. El Director General del Centro Común de Investigación (DG JRC) considera que parte de su función es organizar foros sobre temas complejos, donde los responsables de formular políticas de diferentes campos pueden reunirse, junto con científicos de diferentes disciplinas.

También es importante involucrar a las partes interesadas más afectadas por los fenómenos bajo estudio. El DG JRC está experimentando nuevas formas de involucrar directamente a las partes interesadas en el "codiseño" de las intervenciones públicas. Todo esto es parte del desarrollo de una perspectiva multifacética.

Por último, hay trabajo por hacer para ayudar a los responsables de formular políticas y a los políticos a desarrollar mensajes sencillos para persuadir al público de los méritos de las soluciones que se obtienen al usar ciencia compleja.

Estas son solo algunas reflexiones muy básicas sobre por qué el DG JRC da la bienvenida a este evento. Estamos interesados en ampliar aún más nuestra cooperación con la OCDE y el Instituto para el Nuevo Pensamiento Económico en el área de Complejidad y Política. Al cooperar más estrechamente, creemos que podemos mejorar aún más el papel de la ciencia en la formulación de políticas en nuestro mundo actual de complejidad cada vez mayor.

\section{Enlaces útiles}

El artículo original sobre Esenciales OCDE, incluidos enlaces y material complementario, puede consultarse en: $h t t p: / / w p \cdot m e / p 2 v 60 D-2 D n$

Consulte la serie completa en: http://oecdinsights.org/?s=NAEC+complexity 


\section{Hormigas, algoritmos y complejidad sin gestión}

por Deborah M. Gordon, Departamento de Biología, Universidad de Stanford

Los sistemas sin control central son de naturaleza ubicua. Las actividades cerebrales, como pensar, recordar y hablar, son resultado de innumerables interacciones eléctricas entre las células. Ningún componente del cerebro le dice al resto de este órgano que piense o recuerde. Yo estudio a las hormigas porque me interesa ver de qué manera los resultados colectivos surgen de las interacciones entre los individuos y cómo el comportamiento colectivo se ajusta a los entornos cambiantes.

Hay más de 14000 especies de hormigas, que viven en colonias formadas por una o más hembras reproductoras, y muchos trabajadores estériles, que son las hormigas que ves caminar de aquí para allá. Aunque las hembras reproductoras se llaman "reinas", no tienen poder ni autoridad política. Una hormiga nunca dirige el comportamiento de otra ni le dice qué hacer. Las colonias de hormigas logran recolectar alimentos, construir y mantener nidos, criar a las crías y lidiar con las colonias vecinas, todo sin un plan.

El comportamiento colectivo de las colonias es generado por una red dinámica de interacciones simples entre hormigas. En la mayoría de las especies, las hormigas apenas pueden ver. Funcionan guiadas principalmente por el olor. Cuando una hormiga se mueve a su alrededor, entra brevemente en contacto con otras hormigas por medio de sus antenas, o puede contactar con un efímero pedazo de un químico volátil recién dejado por otra hormiga. Las hormigas huelen con sus antenas, y cuando una toca a otra con ellas, evalúa si la otra hormiga es de su mismo nido y, a veces, qué tarea ha estado realizando. La hormiga usa su experiencia reciente de interacciones químicas para decidir qué hacer a continuación. En conjunto, estas interacciones simples crean una red en constante cambio que regula el comportamiento de la colonia.

El proceso que genera interacciones simples a partir del comportamiento de una colonia es lo que los expertos en informática llaman un algoritmo distribuido. Ninguna unidad individual, como 
una hormiga o un enrutador en una red de datos, sabe lo que están haciendo todos los demás ni les dice qué hacer. En cambio, las interacciones entre cada unidad y sus conexiones locales se suman al resultado deseado.

Los procesos distribuidos que regulan el comportamiento colectivo de las hormigas están en sintonía con las condiciones ambientales. Por ejemplo, las hormigas cosechadoras del desierto tienen altos costos operativos y su comportamiento está regulado por retroalimentación que limita la actividad a menos que sea necesario. Una colonia debe gastar agua para obtener agua. Las hormigas obtienen agua al metabolizar las grasas contenidas en las semillas que comen. Una recolectora que busca comida bajo el sol del desierto pierde agua. Las colonias manejan esta compensación mediante una forma simple de retroalimentación. Una recolectora que está por salir a trabajar no abandona el nido hasta encontrar suficientes recolectoras que regresen con semillas. Esto tiene sentido porque cada una de ellas busca hasta encontrar comida. Por tanto, cuanta más comida haya disponible, más rápido la encontrarán y regresarán al nido, lo que estimulará a más recolectoras a salir a buscar. Cuando no hay comida disponible, la actividad de recolección de alimentos disminuye. Un estudio a largo plazo de una población de colonias muestra que aquellas que conservan el agua en condiciones de sequía al permanecer en el interior tienen más éxito en la reproducción de colonias descendientes.

Por el contrario, otras especies llamadas "hormigas tortuga", que viven en árboles de selvas tropicales en México, regulan su comportamiento de manera muy diferente. Las hormigas tortuga crean un sistema de senderos que conecta a diferentes nidos y fuentes de alimentos. Los costos operativos son bajos porque la selva tropical es húmeda, pero la competencia de otras especies es alta. Estas hormigas interactúan usando la superficie del suelo para dejar rastros de feromonas dondequiera que vayan. Una hormiga tiende a seguir a otra y esta interacción simple mantiene el flujo de hormigas en marcha, excepto cuando es disuadida por encuentros con otras especies. En condiciones de bajos costos operativos, las interacciones crean retroalimentación que hace que la actividad en curso sea el estado predeterminado, y usa retroalimentación negativa para inhibir la actividad. Este es el opuesto al sistema de las 
hormigas del desierto que requieren retroalimentación positiva para iniciar la actividad.

¿Qué podemos aprender de las hormigas acerca de la sociedad humana? Dichos insectos se han utilizado a lo largo de la historia como ejemplos de obediencia e industria. En la mitología griega, Zeus transforma a las hormigas de Tesalia en hombres y crea un ejército de soldados que se harían famosos como los mirmidones listos para morir por Aquiles (de myrmex u hormiga en griego). En la Biblia (Proverbios 6:6-8), se nos dice "Mira la hormiga" que recoge grano en el verano y lo almacena para el invierno. Pero las hormigas no actúan por obediencia, y no son especialmente laboriosas; de hecho, muchas de ellas pasan el tiempo en el nido sin hacer nada.

Las hormigas y los seres humanos son muy distintos. El poder y la identidad son decisivos para el comportamiento social humano y están ausentes en las hormigas, que no tienen relaciones con otras hormigas como individuos. A una hormiga que evalúa sus interacciones recientes con otras, no le importa si entró en contacto con la hormiga número 522 o la número 677. Y, lo que es aún más significativo, una hormiga no actúa en respuesta a ninguna evaluación de lo que debe hacerse.

Sin embargo, podríamos aprender de las hormigas acerca del comportamiento de redes dinámicas muy grandes centrándonos en el patrón o la estructura de las interacciones y no en el contenido. En tanto que a nosotros nos importa lo que dicen nuestros correos electrónicos, a las hormigas solo les interesa la frecuencia con la que les llegan. Es evidente que muchos procesos sociales humanos funcionan sin control central. Por ejemplo, por doquier vemos los efectos del cambio climático impulsados por muchos procesos sociales diferentes que se basan en el uso de combustibles fósiles. Ninguna autoridad central decidió lanzar emisiones de carbono a la atmósfera, pero los niveles de $\mathrm{CO}_{2}$ son resultado de la actividad humana. Otro ejemplo obvio es la Internet, una enorme red dinámica de interacciones locales en forma de mensajes de correo electrónico $\mathrm{y}$ visitas a sitios web. La función de las redes sociales en las recientes elecciones de Estados Unidos de América refleja cómo la brecha entre las diferentes redes puede generar puntos de vista completamente apartados de lo que sucede y del porqué. 
Las ideas más útiles pueden provenir del análisis de la manera en que la dinámica de los algoritmos distribuidos evoluciona en relación con las condiciones cambiantes. Las correlaciones entre la regulación del comportamiento colectivo y las condiciones cambiantes en las que opera podrían aportar perspectivas e incluso inspirar el pensamiento acerca de las políticas, en los sistemas sociales humanos. Para las hormigas o neuronas, la red no tiene contenido. El estudio de los sistemas naturales puede mostrarnos cómo el ritmo de las interacciones locales crea patrones en el comportamiento y el desarrollo de grandes grupos, y cómo evoluciona esa retroalimentación en respuesta a un mundo cambiante.

\section{Enlaces útiles}

El artículo original sobre Esenciales OCDE, incluidos enlaces y material complementario, puede consultarse en: $h t t p: / / w p \cdot m e / p 2 v 60 D-2 J K$

Consulte la serie completa en: http://oecdinsights.org/?s=NAEC+complexity 


\section{Sortear problemas perversos}

por Julia Stockdale-Otárola, Dirección de Asuntos Públicos

y Comunicaciones de la OCDE

Saber que hay una única solución clara para cualquier problema es sin duda una idea reconfortante. De niños levantamos la mano en clase para responder preguntas cada vez más difíciles, siempre con la esperanza de "hacerlo bien". Pero a veces la pregunta en sí es ambigua y la lista de posibles soluciones es interminable.

Tal es el caso de los problemas perversos.

El término no es un juicio moral. Los problemas perversos son dinámicos, mal estructurados, persistentes y de carácter social. Difíciles de definir, sumamente interconectados con otros problemas sociales y con la participación de muchos actores, los problemas perversos reflejan la complejidad del mundo en el que vivimos. Pensemos, por ejemplo, en retos de política como el cambio climático, la inmigración, la pobreza, la nutrición, la educación o la falta de vivienda. Cada problema implica múltiples factores impulsores, afecta varios campos de política y niveles de gobierno. Para complicar aún más las cosas, cualquier intervención podría desencadenar una cadena de nuevas consecuencias no deseadas. Hablamos de muchas piezas con gran movilidad.

Todos estos factores dificultan que todos concuerden en cuál es el problema real, dónde está arraigado, quién es responsable y cómo solucionarlo mejor. El alcance del problema también es poco claro. Sistemas completos podrían estar relacionados con un problema aparentemente local o regional como el transporte público.

Obviamente, afrontar el problema ya es bastante desafío; entonces, ¿qué hacemos respecto a tomar decisiones? Hasta ahora, los enfoques tradicionales han resultado insatisfactorios. De hecho, muchos de estos problemas perversos parecen empeorar a medida que intentamos resolverlos.

Las complejidades involucradas nos obligan a repensar nuestra estrategia de solución de problemas. En lugar de tratar de encontrar 
una solución final, debemos reconocer que estos retos pueden, en términos generales y en el mejor de los casos, manejarse, pero no resolverse. Al menos, no resolverse en un sentido estático. Eso no significa que la situación no pueda mejorarse; según algunos, incluso podría "resolverse" dependiendo de cómo se defina el problema. La conclusión es que necesitamos ser más flexibles para gestionar mejor los retos que los problemas perversos plantean. Las políticas deben ser adaptativas, de modo que puedan cambiar a medida que el problema evoluciona con el tiempo. También debemos evitar apegarnos demasiado a nuestras propias soluciones, las cuales tienen que ser dinámicas, cambiar junto con el problema en cuestión.

Desde el principio, debemos analizar los problemas de manera más integral. En diferentes campos se está desarrollando un número creciente de nuevos enfoques para ofrecer soluciones. La ciencia de la complejidad es adaptativa por naturaleza, ya que analiza la forma en que los sistemas interactúan. Hasta la fecha, esta estrategia ha sido útil, por ejemplo, para mejorar la gestión del tránsito vehicular. Para mejorar la seguridad en este ámbito, se aplican técnicas analíticas para anticipar riesgos y congestionamientos, y mejorar la circulación. La implementación de proyectos piloto también puede ser útil para abordar problemas perversos, cuando sea asequible, ya que requieren seguimiento continuo y la oportunidad de realizar ajustes. Aunque no existe una fórmula mágica, estos enfoques pueden ayudar a reflejar algunas de las complejidades de los problemas perversos.

Los gobiernos ya comenzaron a utilizar algunas de estas estrategias adaptativa. El gobierno de Singapur puso en marcha una combinación de enfoques de políticas para abordar problemas perversos. Por ejemplo, implementó un enfoque matricial para ayudar a los departamentos a compartir mejor la información y trabajar a nivel horizontal; se establecieron nuevos departamentos que reflejan los problemas más espinosos; y se introdujo una herramienta computarizada para ayudar a mitigar los riesgos sistémicos. Aunque la isla tiene la ventaja de su tamaño, el cual facilita la implementación de nuevos enfoques, sus experiencias pueden proporcionar algunas ideas útiles sobre las mejores prácticas. 
La OCDE también ha considerado los retos de política como problemas perversos. En un taller del 2009 sobre respuestas de políticas a inquietudes sociales, Sandra Batie y David Schweikhardt, de la Universidad Estatal de Michigan, analizaron la liberalización comercial como un problema perverso. En este caso, el papel de las partes interesadas es característico de un problema perverso: es probable que diferentes grupos tengan ideas diferentes sobre cuál es el problema real y cuáles son sus causas. Algunos dirían que el problema es abrir la economía lo más posible, mientras que para otros puede ser más importante proteger la soberanía nacional o proteger a los productores locales.

A diferencia de un problema dócil, en el que los protocolos de base científica orientan la elección de la solución, las respuestas a la pregunta de si se necesita una mayor liberalización del comercio dependen de los juicios y valores de quien responda. Muchos actores sencillamente rechazan razonamientos directos para justificar la liberalización del comercio basada en la economía neoclásica. Batie y Schweikhardt adujeron que el papel de la ciencia, incluida la ciencia económica, no es reducir el rango de opciones a una (en este caso, la liberalización del comercio), sino más bien expandir las opciones para abordar el o los problemas y destacar las consecuencias incluidas las consecuencias distributivas-de opciones alternativas.

Los problemas perversos nos recuerdan que no siempre es fácil, o incluso posible, "hacerlo bien". No siempre existe una solución que pueda implementarse una vez y que dure para siempre. Pero eso está bien. Lo único que necesitamos es dejar de pensar en lograr soluciones óptimas y aprender a sostener soluciones adaptativas.

\section{Enlaces útiles}

El artículo original sobre Esenciales OCDE, incluidos enlaces y material complementario, puede consultarse en: $h t t p: / / w p \cdot m e / p 2 v 60 D-2 D R$

Consulte la serie completa en: http://oecdinsights.org/?s=NAEC+complexity 


\section{Fuera de la complejidad ¿una tercera vía?}

por Bill Below, Dirección de Gobernanza Pública y Desarrollo Territorial de la OCDE

Al sempiterno gruñón H.L.Mencken suele citársele erróneamente con la frase: "Para cada problema complejo hay una respuesta clara, simple y equivocada". La capacidad de simplificar es, por supuesto, una de nuestras fortalezas como seres humanos. Como especie, también podríamos habernos llamado homo redactor: después de todo, pensar es encontrar patrones y organizar la complejidad, reducirla a opciones factibles o convertirla en cosas útiles. Los economistas del comportamiento han identificado una multitud de atajos que usamos para reducir situaciones complejas a información procesable. Estos trucos tan arraigados -o heurística- nos permiten tomar decisiones sobre la marcha, brindando respuestas rápidas a preguntas como “¿debería confiar en ti?” o “¿Es mejor sacar provecho ahora o esperar para hacerlo más adelante?” ¿Son confiables estos trucos? No siempre. Un poco de debida diligencia nunca está de más cuando prestamos atención a nuestros instintos y el valor de identificar la heurística es, en parte, comprender los límites de su utilidad y los posibles puntos ciegos que crea. El caso es que no hay escasez de soluciones a los problemas, ya sea que los generemos nosotros mismos o los recibamos de expertos. Y no hay escasez de planes de acción y de políticas basadas en ellos. Entonces, el problema no es tanto cómo encontrar respuestas, parece que no tenemos mayor problema para hacerlo. La verdadera cuestión es ¿cómo llegamos a las respuestas correctas, particularmente ante una complejidad implacable?

Existe una nomenclatura en la jerarquía de la complejidad, así como formas adecuadas e inadecuadas de resolver problemas en cada nivel. Estas se presentan en la reciente publicación From Transactional to Strategic: Systems Approaches to Public Challenges (OECD, 2017), un estudio del pensamiento sistémico estratégico en el sector público. Desarrollado por IBM en la década de 2000, el marco Cynefin propone cuatro niveles de complejidad de sistemas: obvio, complicado, complejo y caótico. Los retos obvios implican respuestas obvias. Pero los siguientes dos niveles son menos obvios. Si bien tendemos a usar los adjetivos "complicado" y "complejo" 
indistintamente en una conversación informal, el marco impone una distinción formal. Los sistemas o problemas complicados tienen al menos una respuesta y se caracterizan por relaciones causales (aunque a veces ocultas al principio). Los sistemas complejos fluyen constantemente. En sistemas complicados, sabemos lo que no sabemos (incógnitas conocidas) y aplicamos nuestros conocimientos expertos para llenar los vacíos. En sistemas complejos, no sabemos lo que no sabemos (incógnitas desconocidas) y las relaciones de causa y efecto solamente pueden deducirse después de los hechos. Eso no significa que no podamos incursionar en la comprensión e incluso en la configuración de un sistema complejo, pero es necesario utilizar métodos adaptados al reto. Un sesgo común es confundir la complejidad con una mera complicación. El resultado es el exceso de confianza en que la solución está a la vuelta de la esquina y la elección incorrecta de herramientas.

Lamentablemente, los desajustes entre las estructuras organizacionales y las estructuras problemáticas son comunes. Las instituciones tienen competencias específicas y en ocasiones bastante limitadas, y a menudo actúan sin una visión más amplia de lo que otras instituciones están haciendo o planificando. Cada institución puede tener conocimientos expertos específicos pero pocas oportunidades para adoptar enfoques sostenidos y transinstitucionales para resolver problemas complejos.

Por tanto, las estructuras institucionales de arriba-abajo, de comando y control generan su propia resistencia al tipo de enfoque holístico, de gobierno integral que requieren los problemas complejos y el pensamiento sistémico. Esto puede ser producto de la necesidad de estructuras que se adapten eficientemente a los nuevos mandatos en forma de nombramientos políticos que supervisen un núcleo estable de funcionarios públicos profesionales. Además, la presencia de funcionarios electos o nombrados en los niveles superiores de instituciones gubernamentales claramente definidas, puede señalar que se está prestando atención a la voluntad de las personas. La resistencia estructural también puede provenir de ciclos políticos competitivos, lo que desalienta a los candidatos a participar en compensaciones cíclicas intertemporales o comprometerse con proyectos con metas complejas. En un mundo de entrevistas fragmentadas, noticias falsas y tácticas de arrasamiento, un enfoque 
de sistemas razonado, metódico y abierto puede ser un objetivo político mayor y lento.

Y ese es el reto de abordar problemas complejos y "perversos" con el apoyo y el alcance institucionales adecuados; debe haber menos revoluciones radicales o clamor de fracaso total por parte de la oposición. Las interrupciones dan paso al progreso continuo a medida que el sistema complejo evoluciona desde adentro. Es una especie de tercera vía que evita la polarización y favorece la colaboración, que combina los principios del mercado con lo que podría llamarse "orientación estatal" en lugar de intervención desde arriba o descendente.

El calentamiento global, las políticas para la población en proceso de envejecimiento, los servicios de protección a la infancia y la gestión del transporte son ejemplos de retos y sistemas complejos. Los sistemas complejos son difíciles de definir desde el principio y su alcance es ilimitado. Solo pueden modificarse gradualmente, componente por componente, subsistema por subsistema, aprendiendo de múltiples circuitos de retroalimentación, midiendo lo que funciona y evaluando cuánto más nos acerca a nuestros objetivos.

La Teoría General de Sistemas (TSG), es decir, el pensamiento acerca de los aspectos característicos de los sistemas en sí, surgió de una nueva era tecnológica audaz en la que los campos individuales de ingeniería ya no bastaban para dominar la impresionante gama de conocimientos y habilidades requeridos por la integración de sistemas emergentes. Ese conocimiento práctico hizo aportaciones complejas tan temibles como el Misil Balístico Intercontinental y tan inspiradoras como el vuelo espacial tripulado. Hoy, el mundo parece sufrir de fatiga de complejidad, cuyos síntomas son el anhelo de respuestas simples y un mundo libre de interdependencias, con claros ejemplos de personas buenas y malas, y voces impetuosas e inquebrantables que "dicen las cosas tal como son", un mundo con líneas trazadas, muros construidos y fronteras cerradas. Recuperar una sensación de emoción y propósito al dominar la complejidad puede ser el primer problema "perverso" que debemos resolver. 
Mientras tanto, necesitamos encontrar una manera de dejar de afrontar retos complejos a través de los límites de nuestras instituciones y comenzar a hacerlo a través de sus propios contornos. De lo contrario, demasiadas decisiones importantes serán claras, simples y equivocadas.

\section{Enlaces útiles}

El artículo original sobre Esenciales OCDE, incluidos enlaces y material complementario, puede consultarse en: http://wp.me/p2u6oD-2Or

Consulte la serie completa en: http://oecdinsights.org/?s=NAEC+complexity 
Complejidad y economía 


\section{Complejidad y política económica}

por Alan Kirman, École des hautes études en sciences sociales, París, y Aix-Marseille University

Durante los últimos dos siglos ha habido una creciente aceptación del liberalismo social y político como la base deseable para la organización social. La teoría económica ha intentado adaptarse a esa posición y ha desarrollado modelos cada vez más sofisticados para justificar el argumento de que las personas abandonadas a su suerte se autoorganizarán en un Estado socialmente deseable. Sin embargo, al hacerlo, nos ha conducido a una visión del sistema económico que está en desacuerdo con lo que ha sucedido en muchas otras disciplinas.

Si bien en campos como la física estadística, la ecología y la psicología social ahora se acepta ampliamente que los sistemas de individuos interactuantes no tendrán el tipo de comportamiento que corresponde al de una partícula o individuo promedio o característico, esto no ha tenido mucho efecto en la economía. En tanto que esas disciplinas procedieron a estudiar la aparición de dinámicas no lineales como resultado de la compleja interacción entre las personas, los economistas insistieron sin cesar en basar su análisis en que las personas con optimización racional se comportan como si actuaran en total aislamiento. De hecho, este es el paradigma básico en el cual se basan la teoría económica moderna y nuestros modelos económicos estándar. Data del concepto de Adam Smith (1776) de la mano invisible que sugería que cuando se deja a las personas, en la medida de lo posible, a su suerte, la economía se autoorganizará en un estado con propiedades de bienestar satisfactorias.

Sin embargo, este paradigma no está validado por evidencia empírica ni tiene fundamentos teóricos sólidos. Se ha convertido en un supuesto. Ha sido la piedra angular de la teoría económica, aunque la persistente llegada de grandes crisis económicas parecería sugerir que existen problemas reales con el análisis. La experiencia sugiere que la amnesia prevalece entre los economistas y que, si bien cada crisis provoca demandas de nuevos enfoques a la economía (como muestra el nacimiento del Institute for New Economic Thinking [Instituto para el Nuevo Pensamiento Económico] de George Soros), al final prevalecen la inercia y la economía vuelve al camino que ya seguía. 
Ha habido una notoria tendencia a utilizar un periodo de relativa calma para declarar la victoria sobre el enemigo. Recordemos la declaración de Robert Lucas, ganador del Premio Nobel y Presidente de la Asociación Económica Americana en su discurso presidencial en 2003: "El problema central de la depresión-prevención se ha resuelto".

Tanto los economistas como los responsables de formular políticas habían sido engañados por una sensación de falsa seguridad durante este breve periodo de calma.

Después llegó 2008 y, como siempre sucede en tiempos de crisis, se alzaron voces, principalmente de analistas y responsables de formular políticas, que preguntaban por qué los economistas no habían anticipado el inicio ni la gravedad de la crisis.

Cuando la reina Isabel II preguntó a los economistas de la London School of Economics qué había salido mal, recibió la siguiente respuesta: "En resumen, Su Majestad, la falta de previsión del momento, el alcance y la gravedad de la crisis... fue principalmente la falta de imaginación colectiva de muchas personas brillantes... para comprender los riesgos para el sistema en su conjunto".

Tan pronto como se considera la economía como un sistema adaptativo complejo en el que el comportamiento conjunto surge de la interacción entre sus componentes, no se puede establecer una relación simple entre el participante individual y el conjunto. Debido a todas las interacciones y las realimentaciones complicadas entre las acciones de los individuos y el comportamiento del sistema, inevitablemente habrá "consecuencias imprevistas" de las acciones emprendidas por las personas, las empresas y los gobiernos. No solo las propias personas sino la red que las vincula cambian con el tiempo. La evolución de dichos sistemas es intrínsecamente difícil de predecir, y para los responsables de formular políticas públicas esto significa que afirmaciones como "Esta medida causará ese resultado" tienen que ser reemplazadas por "Hay varios resultados posibles y nuestras mejores estimaciones de las probabilidades de ellos en el punto actual son..."

Consideremos el caso del posible impacto del Brexit en la economía británica y en la economía global. Ahora se emiten 
pronósticos modificados del crecimiento de estas economías, pero cuando tanto depende de las condiciones bajo las cuales se logre la salida, ¿es razonable hacer tales pronósticos deterministas? Dadas la complejidad y la naturaleza interconectada de las economías, los factores políticos que influirán en la naturaleza de la separación, y la percepción y anticipación de los participantes (desde los individuos hasta los gobiernos) de las consecuencias, ¿cuánta confianza podemos sentir en las estimaciones puntuales de crecimiento en los próximos años?

Si bien algunos pueden interpretar el enfoque de sistemas complejos como una admisión de nuestra incapacidad de controlar o incluso influir en los resultados económicos, esto no tiene por qué ser así. Hayek alegó alguna vez que no hay "leyes" económicas, solo "modelos". El desarrollo de los macrodatos y las técnicas para su análisis pueden proporcionarnos las herramientas para reconocer dichos modelos y reaccionar ante ellos. Pero estos modelos surgen de la interacción de individuos que en muchos aspectos son más simples que el homo economicus, y es la interacción entre estos individuos relativamente simples que reaccionan a lo que está sucediendo, en lugar de optimizar de forma aislada, la que produce los principales trastornos que caracterizan a nuestros sistemas.

Finalmente, intentar estabilizar esos sistemas, es un error centrarse en una variable, ya sea para controlar el sistema o para informarnos sobre su evolución. Las variables individuales, como la tasa de interés, no permiten tener suficiente flexibilidad para las acciones de las políticas y las medidas de desempeño únicas, como la tasa de desempleo o el PIB, transmiten muy poca información sobre el estado de la economía.

\section{Enlaces útiles}

El artículo original sobre Esenciales OCDE, incluidos enlaces y material complementario, puede consultarse en: $h t t p: / / w p . m e / p 2 v 60 D-2 B 4$

Consulte la serie completa en: http://oecdinsights.org/?s=NAEC+complexity 


\title{
Un holista pragmático: Herbert Simon, economía y la arquitectura de la complejidad
}

por Vela Velupillia, Escuela de Economía de Madrás

\author{
"Herb armó todas las piezas hace por lo menos 40 ańos, y lo \\ conozco desde hace solamente 35 años." Alan Newell, 1989.
}

Y así fue, con los artículos Jerarquía en 1950, Cuasi Descomponibilidad de alrededor de 1949, y Causalidad, que sustentan la evolución razonablemente rápida de los sistemas dinámicos en una serie de estructuras complejas estables. Casi todos estos artículos pioneros están reimpresos en la colección de Simon de 1977 y, además, los clásicos de la jerarquía y la casi descomposición aparecen en la sección 4 con el título "Complejidad". La visión cibernética se convirtió en la base informática digital completa de los responsables de solucionar problemas humanos racionalmente acotados que implementan procedimientos de búsqueda heurística para probar, por ejemplo, teoremas matemáticos axiomáticos (en los monumentales libros de Principia Mathematica de Russell y Whitehead) que corroboran la afirmación completamente razonable de Alan Newell antes citada.

Al definir el concepto de complejidad en la obra The Architecture of Complexity (AoC), Simon evita los formalismos y se basa en un concepto aproximado y funcional de sistemas complejos que ayudaría a identificar ejemplos de estructuras observables - sobre todo en las ciencias del comportamiento- que podrían traducirse en teorías y, por tanto, teoremas, de sistemas dinámicos en evolución que exhiben propiedades susceptibles de diseño y predicción con la ayuda de la jerarquía, la cuasi descomponibilidad y la causalidad. Por ende, la definición casi informal es (cursivas agregadas): "Aproximadamente, por un sistema complejo me refiero a uno conformado por una gran cantidad de partes que interactúan de una manera no simple. En tales sistemas, el todo es más que la suma de las partes... en el... sentido pragmático de que, dadas las propiedades de las partes y las leyes de su interacción, no es una cuestión trivial inferir las propiedades del 
todo. Ante la complejidad, un reduccionista en principio puede ser al mismo tiempo un holista pragmático".

Simon siempre fue un holista pragmático, incluso mientras intentaba reducir el comportamiento de entidades complejas a procesos parsimoniosos que exhibirían las propiedades de las "totalidades", basadas en "partes" que no interactúan simplemente, que pueden en sí ser simples. Resumió la forma en que este enfoque podría aplicarse a la economía en una carta dirigida al profesor Axel Leijonhufvud y a mí después de leer mi libro Computable Economics. (Consúltese la carta aquí.) Simon adujo lo siguiente:

"Por último, llegamos al límite empírico... del nivel de complejidad que los humanos realmente pueden manejar, con y sin sus computadoras, y —quizá más importante-, lo que en realidad hacen para resolver problemas que se encuentran más allá de este límite estricto, aunque estén dentro de algunos de los límites más amplios.

Este último es un punto importante para la economía, porque los humanos pasamos la mayor parte de nuestra vida tomando decisiones que están más allá de cualquiera de los niveles de complejidad que podemos manejar con exactitud; y aquí es donde se hacen cargo los niveles satisfactorios (satisficing) de aspiración flotante, el reconocimiento y la búsqueda heurística, y mecanismos similares para llegar a decisiones suficientemente buenas. [En Rational Choice and the Structure of the Environment (Elección Racional y la Estructura del Entorno) Simon (1956) utilizó el término satisficing, tomándolo prestado del Oxford English Dictionary donde aparece como un sinónimo de satisfying (satisfacer) utilizado en Northumbria, con el que describió una estrategia para tomar una decisión que el decisor considera adecuado, incluso si en teoría no es óptimo.] Una teoría económica parsimoniosa, y una teoría empíricamente verificable, muestra cómo los seres humanos, usando procedimientos muy sencillos, toman decisiones que van mucho más allá de su capacidad para encontrar soluciones exactas mediante los criterios habituales de maximización".

En muchos sentidos, el AoC resumió las visiones evolutivas (sic) de Simon de una ciencia conductual cuantitativa, que proporcionó las 
bases para administrar organizaciones complejas, jerárquicamente estructuradas y causales, mediante agentes limitadamente racionales que implantaron, con la ayuda de computadoras digitales, procedimientos que eran, a su vez, reflejos de procesos de resolución de problemas humanos. Pero también presagiaba la precisión cada vez mayor de la realidad predecible -que no equivalía a fenómenos no pragmáticos y no empíricos-que requería una descripción operativa de los sistemas complejos que eran de naturaleza observable, como resultado de la dinámica evolutiva de las estructuras jerárquicas. Por tanto, en la sección final del AoC, la cuarta, se "examina la relación entre los sistemas complejos y sus descripciones", para lo cual Simon regresó a la definición pionera de Solomonoff de la teoría de la información algorítmica.

El AoC fue igualmente expositivo sobre los muchos problemas con los que hemos llegado a asociar a los agentes (e instituciones) limitadamente racionales de Simon que satisfacen, en lugar de optimizar, de nuevo por razones pragmáticas, históricamente observables y realistas - utilizando procesos de búsqueda heurística en contextos de decisiones conductuales de resolución de problemas humanos. La famosa distinción entre racionalidad sustantiva y procesal surgió de la dicotomía de una descripción de un estado versus una descripción de proceso de un mundo "que se percibe y... respecto al cual se actúa".

Esencialmente, el AoC está impregnado de definiciones pragmáticas y procedimientos humanos de implementaciones realistas, incluso en el uso de computadoras digitales. La teoría de la computabilidad asume la Tesis de Church-Turing en la definición de algoritmos. El concepto de complejidad computacional se basa en el supuesto de la validez de la Tesis de Church-Turing. Los algoritmos de Simon para resolver problemas humanos son procesos de búsqueda heurísticos, donde no se hace tal suposición. De ahí que no sea sorprendente la sensación que lo envolvió en sus últimos años (cursivas agregadas):

"El campo de la informática se ha ocupado mucho con cuestiones de complejidad computacional, el opuesto de la simplicidad computacional. Pero en la literatura sobre la materia, "complejidad" generalmente significa algo muy diferente de mi significado en 
el contexto actual. Principalmente por razones de accesibilidad matemática, y a costa de la relevancia, los teoremas de la complejidad computacional han abordado sobre todo el comportamiento en el peor de los casos de los algoritmos computacionales a medida que el tamaño del conjunto de datos aumenta. En el límite, incluso se han centrado en la computabilidad en el sentido de Gödel y Turing y el problema de la detención. Debo confesar que estas preocupaciones me producen un gran sentimiento de hastío."

\section{Enlaces útiles}

El artículo original sobre Esenciales OCDE, incluidos enlaces y material complementario, puede consultarse en: $h t t p: / / w p \cdot m e / p 2 v 60 D-2 \mathrm{Lg}$

Consulte la serie completa en: http://oecdinsights.org/?s=NAEC+complexity 


\section{De la crisis económica a la crisis en economía}

por Andy Haldane, Economista en Jefe y Director Ejecutivo, Análisis Monetario y Estadística, Banco de Inglaterra

Sería fácil deprimirse mucho con el estado de la economía en el entorno actual. A muchos expertos, incluidos aquellos en economía, simplemente se les ignora. Pero los retos económicos que enfrentamos no podrían ser mayores: desaceleración del crecimiento, desaceleración de la productividad, retroceso del comercio, retroceso de la globalización, niveles altos y crecientes de desigualdad. Se trata de problemas profundos y diversos que enfrentan nuestras sociedades y necesitaremos marcos profundos y diversos para ayudar a comprenderlos y establecer políticas en respuesta a ellos. En el entorno anterior a la crisis, cuando la situación era relativamente estable y estacionaria, nuestros marcos existentes de macroeconomía consiguieron darle sentido a las cosas.

Pero el mundo actual se caracteriza por rasgos como discontinuidades, puntos de inflexión, equilibrios múltiples e incertidumbre radical. De tal forma, si queremos hacer que la economía resulte interesante y la respuesta a los retos sea adecuada, necesitamos nuevos marcos que capturen las complejidades de las sociedades modernas.

Estamos viendo un mayor interés en usar la teoría de la complejidad para dar sentido a la dinámica de los sistemas económicos y financieros. Por ejemplo, se han empleado modelos epidemiológicos para comprender y evaluar los estándares de capital regulatorio para los bancos más grandes e interconectados, los denominados "súper difusores". Se ha prestado menos atención al uso de la teoría de la complejidad para comprender la arquitectura general de las políticas públicas: cómo las diversas piezas del rompecabezas de políticas encajan en su conjunto en relación con los sistemas económicos y financieros modernos. Estos últimos pueden caracterizarse como un "sistema de sistemas" complejo y adaptativo, un conjunto anidado de subsistemas, cada uno en sí mismo una red compleja. La arquitectura de un sistema de sistemas complejo significa que para comprender y moderar las fluctuaciones se requieren políticas con diversos grados de amplificación. También 
significa que al valorar el riesgo es importante tomar en cuenta las interacciones entre estos estratos.

Aunque no existe una definición de complejidad aceptada de manera general, la propuesta por Herbert Simon en The Architecture of Complexity: "algo hecho de un gran número de partes que interactúan en una forma no-simple", refleja bien su esencia cotidiana. El todo se comporta de manera muy diferente a la suma de sus partes. Las propiedades de los sistemas complejos suelen dar lugar a distribuciones estadísticas irregulares, y a menudo altamente no normales, para estos sistemas a lo largo del tiempo. Esto se hace manifiesto en forma de colas mucho más amplias de lo que sugeriría una distribución normal. En otras palabras, las interacciones y retroalimentaciones de todo el sistema generan una probabilidad mucho mayor de eventos catastróficos de lo que implicarían las distribuciones gaussianas.

Por razones evolutivas de supervivencia del más apto, Simon postuló que las redes "descomponibles" eran más resilientes $\mathrm{y}$, por tanto, más propensas a proliferar. Con el término redes descomponibles se refería a estructuras organizacionales que podrían dividirse de manera tal que la resiliencia del sistema en su conjunto no dependiera de ningún subelemento. Esta puede ser una descripción razonable a largo plazo de algunos sistemas complejos del mundo real, pero menos adecuada como una descripción de la evolución de los sistemas socioeconómicos. La eficiencia de muchas de las redes actuales depende de su hiperconectividad. Hay, en el lenguaje de la economía, un aumento significativo de los rendimientos a escala y de alcance en una industria de redes. Pensemos en los beneficios de las cadenas globales de suministro y las redes interbancarias mundiales para el intercambio de riesgos comerciales y financieros. Esto proporciona un poderoso incentivo secular para los sistemas socioeconómicos no descomponibles.

Además, si estas redes hiperconectadas se enfrentan a una amenaza sistémica, a menudo pueden adaptarse en formas que eviten la extinción. Por ejemplo, el riesgo de desorden social, económico o financiero suele causar la adaptación de las políticas para prevenir el colapso sistémico. Estas respuestas adaptativas de política pueden preservar topologías socioeconómicas de lo 
contrario frágiles. Incluso pueden alentar aún más el crecimiento de la conectividad y la complejidad de estas redes. Por ejemplo, las políticas de apoyo a los bancos "súper difusores" durante una crisis pueden alentarlos a ampliarse y adquirir mayor complejidad. La combinación de las economías de red y las respuestas de política al fracaso significa que los sistemas socioeconómicos pueden ser menos darwinianos y, por tanto, descomponibles, que los sistemas naturales y biológicos.

¿Qué implicaciones de política pública se derivan de este complejo sistema de perspectiva de sistemas? Primero, subraya la importancia de contar con datos precisos y el delineamiento oportuno de cada estrato del sistema. Esto es especialmente importante para reflejar las interacciones dentro y entre estos subsistemas complejos.

En segundo lugar, es probable que el modelaje de cada uno de estos estratos y su interacción con otros estratos sea importante, tanto para comprender los riesgos y la dinámica del sistema como para valorar las posibles respuestas de política a ellos.

En tercer lugar, al controlar estos riesgos, es probable que se aplique una fórmula similar a la Regla de Tinbergen: para monitorear el riesgo y gestionarlo con eficacia es probable que se necesite al menos tantos instrumentos de política como subcomponentes complejos de un sistema de sistemas haya. Dicho de otra manera, es probable que un sistema de sistemas complejo poco identificado resulte en una pérdida de control, tanto en todo el sistema como en cada uno de los estratos.

Mientras tanto, hay una crisis en la economía. Para algunos, es una amenaza. Para otros, es una oportunidad para dar un gran salto adelante, como lo hizo Keynes en la década de 1930. Pero aprovechar dicha oportunidad requiere primero un nuevo examen de los contornos de la economía y una exploración de algunas nuevas vías. En segundo lugar, es importante observar los sistemas económicos a través de una lente interdisciplinaria. Aprovechar los conocimientos de diversas disciplinas, tanto naturales como de las ciencias sociales, puede aportar una perspectiva diferente del comportamiento individual y la dinámica de todo el sistema. 
La iniciativa Nuevos Enfoques ante los Retos Económicos (NAEC) lo hace, y la disposición de la OCDE a considerar un enfoque de complejidad coloca a la Organización a la vanguardia para llevar la formulación de políticas de análisis económico al siglo XXI.

Este artículo se basa en las contribuciones a la Mesa Redonda NAEC organizada por la OCDE el 14 de diciembre de 2016; la Conferencia Conmemorativa Bienal GLS Shackle del 10 de noviembre de 2016; y "Sobre microscopios y telescopios", en el taller del Centro Lorentz, Leiden, sobre complejidad socioeconómica el 27 de marzo de 2015.

\section{Enlaces útiles}

$\mathrm{El}$ artículo original sobre Esenciales $\mathrm{OCDE}$, incluidos enlaces y material complementario, puede consultarse en: $h t t p: / / w p \cdot m e / p 2 v 60 D-2 M 4$

Consulte la serie completa en: http://oecdinsights.org/?s=NAEC+complexity 


\title{
Teoría de la complejidad y economía evolutiva
}

\author{
por Robert D. Atkinson, Presidente, Information Technology
} and Innovation Foundation

Si había algún posible aspecto positivo de la destrucción derivada de la crisis financiera y la Gran Recesión era que la hegemonía intelectual de la economía neoclásica comenzó a ser seriamente cuestionada. De ahí que el creciente interés en la teoría de la complejidad sea un avance positivo. Ciertamente, abordar la política económica desde la perspectiva de la complejidad promete importantes mejoras. Sin embargo, esto solo ocurriría si evitamos una pasividad hayekiana basada en la idea de que la acción es demasiado riesgosa justo por la complejidad de los sistemas económicos. Este sería un error significativo, pues el riesgo de la inacción en los sistemas complejos suele ser mayor que el riesgo de la acción, en especial si esta última es sustentada por un pensamiento riguroso basado en una sólida argumentación.

Los defectos de la economía neoclásica se han señalado desde hace tiempo, incluida la creencia de que la "economía es como una máquina", en la cual, si los responsables de formular políticas tiran de una palanca obtienen un resultado esperado. Sin embargo, a pesar de lo que ha escrito Larry Summers, la economía no es una ciencia que funciona en cualquier momento y lugar. Es una doctrina y, así como la economía evoluciona, también deberían hacerlo las doctrinas. Después de la Segunda Guerra Mundial, cuando Estados Unidos de América estaba cambiando de lo que Michael Lind llama la segunda república (el sistema de gobierno posterior a la Guerra Civil) a la tercera república (la estructura de gobierno de la Gran Sociedad, posterior al New Deal) había un intenso debate intelectual acerca de la ruta de la economía política que Estados Unidos debía tomar. En Keynes-Hayek: The Clash That Defined Modern Economics, Nicholas Wapshott describió este debate entre Keynes (partidario de la tercera república), quien expresaba la necesidad de un Estado más grande y más intervencionista, y Hayek (defensor de la segunda república), quien se preocupaba por la extralimitación del Estado. Actualmente, requerimos un gran debate similar sobre el futuro de las políticas económicas para la "cuarta república" emergente. 
Si deseamos desarrollar tal doctrina económica para guiar el sistema económico sociotécnico actual, la complejidad deberá desempeñar un papel fundacional. Pero un riesgo de ir por el camino de la complejidad es que los proponentes puedan sustituir una ideología por otra. Si los actuales responsables de formular políticas creen que los sistemas económicos son relativamente simples y que las políticas generan solo efectos de primer orden, los responsables de formular políticas que han adoptado la complejidad pueden considerar que los efectos de segundo, tercero y cuarto órdenes proliferan. En otras palabras, la mariposa en México puede desatar un tornado en Texas. Si el asunto es así de complejo, conviene seguir el consejo de Hayek de intervenir lo menos posible. Por lo menos desde un punto de vista mecanicista, los responsables de formular políticas sentían que podían hacer algo, y quizás estaban en lo correcto. Los riesgos de la complejidad hayekianos provocan inacción.

Esto trae consigo un segundo reto: el "pensamiento de grupo". Muchos defensores de la complejidad señalan que las herramientas financieras complejas (como las obligaciones de deuda garantizadas, ODG o CDO, por sus siglas en inglés) son causantes de la crisis financiera. Los reguladores sencillamente no tenían ninguna idea debido a la complejidad de los instrumentos. Pero dichas herramientas eran síntomas. El punto central de la crisis, por lo menos en Estados Unidos, fue el otorgamiento fraudulento de hipotecas. El problema aún más serio fue intelectual: prácticamente todos los economistas neoclásicos adoptaron la teoría de que, en un mercado eficiente, toda la información que permitiría a un inversionista predecir el próximo movimiento de precios ya está reflejada en el precio vigente. Si los precios de la vivienda aumentan $80 \%$ en solo unos años, su valor real aumentó $80 \%$. Así, cualquier reajuste de la economía tiene que basarse no solamente en el reemplazo de los principios básicos de la economía neoclásica, sino también en el reemplazo de una tendencia problemática hacia el pensamiento de grupo. Sin embargo, reemplazar lo primero puede, de hecho, ser más difícil que esto último.

Entonces, ¿hacia dónde vamos con la complejidad? Creo que un componente central de esta es y debe ser la evolución. Desde una perspectiva evolutiva, una economía es un "organismo" que constantemente desarrolla nuevas industrias, tecnologías, 
organizaciones, ocupaciones y competencias, y al mismo tiempo se deshace de las antiguas, que las nuevas tecnologías y otros cambios evolutivos vuelven redundantes. Esta tasa de cambio evolutivo difiere en el tiempo y el espacio, dependiendo de diversos factores, incluidos los adelantos tecnológicos, las iniciativas empresariales, las políticas nacionales y el entorno competitivo internacional. En la medida en que los modelos neoclásicos consideren el cambio, este se contempla más como crecimiento que como evolución. En otras palabras, las transacciones de mercado maximizan la eficiencia estática y el bienestar del consumidor. Como sostiene Alan Blinder: “¿Pueden las actividades económicas reorganizarse de tal modo que la condición de algunas personas mejore, pero ninguna empeore? De ser así, hemos descubierto una ineficiencia. Si no, el sistema es eficiente".

En la economía de la complejidad o evolutiva, deberíamos enfocarnos no en la eficiencia distributiva estática, sino en la eficiencia adaptativa. Douglass North afirma lo siguiente: "La eficiencia adaptativa [...] se ocupa de los tipos de reglas que configuran la manera en que una economía evoluciona en el tiempo. Se ocupa también de la disposición de la sociedad para adquirir conocimiento y aprendizaje, para inducir la innovación, para asumir el riesgo y emprender actividades creativas de todo tipo, así como para resolver problemas y cuellos de botella de la sociedad a través del tiempo". Asimismo, en su libro de 1982, An Evolutionary Theory of Economic Change, Richard Nelson y Sidney G. Winter dijeron: "Las connotaciones más amplias del término "evolutiva" incluyen el interés por los procesos de cambio progresivo y a largo plazo".

Esto ofrece una dirección valiosa. Significa que un enfoque clave para la política económica debería ser incentivar la adaptación, la experimentación y la toma de riesgos. Significa apoyar políticas para acelerar de manera intencional la evolución económica, sobre todo desde la innovación tecnológica e institucional. Esto significa no solo rechazar el neoludismo en favor del optimismo tecnológico, sino adoptar una política de innovación proactiva. Implica también facilitar nuevos experimentos en política, reconocer que muchos fracasarán, pero que algunos tendrán éxito y se convertirán en “especies dominantes". La experimentación en la política y los programas propiciará que la política económica brinde más apoyo a los sistemas adaptativos complejos. 


\section{Enlaces útiles}

El artículo original sobre Esenciales OCDE, incluidos enlaces y material complementario, puede consultarse en: http://wp.me/p2v6oD-2Df

Consulte la serie completa en: http://oecdinsights.org/?s=NAEC+complexity 


\section{Complejidad, modestia y política económica}

por Lex Hoogduin, Universidad de Groningen y GloComNet

Las sociedades y las economías son sistemas complejos, pero las teorías utilizadas para sustentar las políticas económicas desatienden predominantemente la complejidad. Dan por sentado, por ejemplo, a agentes representativos tales como los consumidores habituales y también suponen que el futuro es riesgoso en lugar de incierto. Ese supuesto da lugar a la aplicación del cálculo de probabilidades y a toda una gama de técnicas distintas basadas en él.

En situaciones de riesgo es factible conocer todos los posibles resultados de una política. Esto no sucede en las situaciones de incertidumbre, pero los seres humanos, incluidos los responsables de formular políticas, forzosamente tienen que tomar decisiones y actuar ante un futuro incierto. El argumento tiene lógica. Los seres humanos no pueden saber lo que se descubrirá en el futuro. Sin embargo, los descubrimientos futuros pueden impactar y modelar las consecuencias de sus decisiones y acciones actuales. Por tanto, no tienen la capacidad de proponer una lista exhaustiva de posibles resultados de una decisión o acción de política.

Considerar adecuadamente la complejidad de la economía y la incertidumbre del futuro implica un cambio de paradigma en la economía. Dicho paradigma no tiene que ser desarrollado desde cero. Parte de la ciencia de la complejidad moderna, de la escuela neoaustriaca de economía (en particular Hayek y von Mises), así como del trabajo de Keynes y Knight y algunas vertientes de la psicología cognitiva (por ejemplo, Kahneman, 2011). No hay lugar aquí para profundizar en la teoría y en la afirmación que conlleva un cambio de paradigma. Más bien, analizaré las implicaciones de la aplicación de este paradigma para la política económica.

El tema empieza con el reconocimiento de que el futuro no puede predecirse en detalle. Deberíamos ser modestos acerca de lo que se puede lograr con la política económica. Este es el "principio de modestia". La política económica no puede ofrecer objetivos específicos en cuestión de crecimiento económico, distribución del ingreso, inflación, aumento de la temperatura promedio dentro de 
cuatro décadas, entre otros. Sería sensato que los responsables de formular la política económica dejaran de pretender que son capaces de cumplir con lo que no pueden cumplir. Esta perspectiva implica que muchas políticas actuales deberían descontinuarse. Por mencionar solo un ejemplo: la inflación objetivo por parte de los bancos centrales no pasa este examen de modestia.

Este principio también implica abstenerse de hacer pronósticos económicos minuciosos como una base para la formulación y ejecución de políticas. Las políticas públicas no deberían elaborarse bajo el supuesto de que conocemos el valor de algunas variables que no podemos conocer. Un ejemplo de esto es el multiplicador de ingresos en relación con los cambios en política fiscal. El principio de modestia también emite señales de alarma con la regulación y la supervisión basadas en riesgos.

Lo que la economía política puede hacer es contribuir a la formación y la evolución de un orden económico adecuado, y evitar hacer daño a este (lo que llamaría el "principio de no causar daño") y, hasta donde sea posible, procurar no ser una fuente de incertidumbre para los agentes económicos privados.

El orden es un concepto central en el paradigma alternativo, que reemplaza el concepto de (des)equilibrio en la economía convencional. Un orden es el conjunto de resultados generales posibles (patrones, como crecimiento, inflación, fluctuaciones cíclicas y otros) que surgen de individuos que actúan e interactúan deliberadamente sobre la base de un conjunto de reglas en un sentido amplio (leyes, ética, convenciones...), que en conjunto se llaman régimen. La economía puede analizar la conexión entre los cambios en el régimen y los cambios en el orden económico. La política económica puede influir en el orden económico mediante el cambio de régimen.

Sin embargo, este conocimiento no es incuestionable. Siempre existeunpotencialparasorpresas(positivasynegativas;oportunidades y amenazas) y consecuencias involuntarias. Por consiguiente, no es posible diseñar primero la política y luego simplemente ejecutarla tal como se diseñó. La formulación y ejecución de políticas tiene que evolucionar para convertirse en un proceso de constante supervisión 
y adaptación. Esto también permitiría el cambio evolutivo. Un orden económico al que no se le permite evolucionar podría perder su idoneidad y colapsarse repentinamente o entrar en una crisis (como lo describe Scheffer para las transiciones decisivas en la sociedad). Este mecanismo puede haber intervenido en la Gran Moderación que llevó a la crisis financiera de 2007-2008 y a la crisis de los sistemas de pensión totalmente financiados. También es una advertencia contra la práctica de basar las políticas de sostenibilidad en temperaturas objetivo precisas dentro de décadas en el futuro ignoto.

La idoneidad del orden tiene cinco dimensiones. La primera es un orden en el cual los agentes actúan como se describió en el párrafo anterior: la elaboración de políticas públicas involucra un proceso de supervisión y adaptación constantes. Además, la idoneidad se determina por el estado de alerta de los agentes (capacidad de detectar errores y oportunidades); su resiliencia (capacidad de sobrevivir y recuperarse de errores y sorpresas negativas); la capacidad adaptativa (capacidad de ajustarse), y la capacidad creativa (la capacidad de imaginar y modelar el futuro). Las políticas pueden dirigirse a facilitar a los agentes económicos la mejora de estas capacidades, aunque restringida por los principios de "modestia" y "de no causar daño". Obsérvese que el concepto de estabilidad no aparece en la definición de idoneidad. Esto marca una diferencia frente a las políticas actuales, las cuales ponen mucho énfasis en la estabilidad.

El gobierno deberá ser transparente y predecible en sus propias acciones. Parece ser que la mejor manera de hacerlo es seguir reglas sencillas. Por ejemplo, en política fiscal, equilibrar el presupuesto, quizá con espacio limitado y claramente definido para que los estabilizadores automáticos funcionen.

Este paradigma alternativo destaca algunos métodos y técnicas analíticos, entre ellos técnicas narrativas, análisis de redes, lógica evolutiva, concepción de escenarios cualitativos, dinámicas no lineales (Scheffer), análisis histórico (el desarrollo de sistemas complejos depende de la trayectoria) y pruebas de resistencia (inversas). 
Las políticas económicas desarrolladas dentro de estos parámetros ayudan a las personas a vivir la vida como lo desean. Son buenas políticas para una buena vida.

\section{Enlaces útiles}

El artículo original sobre Esenciales OCDE, incluidos enlaces y material complementario, puede consultarse en: $h t t p: / / w p \cdot m e / p 2 v 60 D-2 C F$ Consulte la serie completa en: http://oecdinsights.org/?s=NAEC+complexity 


\section{La creciente complejidad de la economía global}

por Sony Kapoor, Director Ejecutivo, Re-Define International Think Tank y CEO de Court Jesters Consulting

Un sistema complicado (como un automóvil) puede desarmarse y entenderse como la suma de sus partes. En cambio, un sistema complejo (como el tránsito) tiene características emergentes que surgen de la interacción entre sus partes constituyentes. Aplicar la teoría de la complejidad a la elaboración de políticas económicas requiere este importante reconocimiento: que la economía no es un sistema complicado, sino complejo.

Históricamente, los modelos económicos y la formulación de políticas correspondiente han tratado a la economía como un sistema complicado en el que modelos estilizados y simplificados, a menudo aplicados a una economía cerrada, a un sector específico o dirigida solamente a canales particulares de interacción como las tasas de interés, buscan primero simplificar la economía real, y después comprenderla, para finalmente generalizarla con el fin de elaborar políticas.

Este enfoque es cada vez más obsoleto y producirá resultados que sencillamente no lograrán reflejar la creciente complejidad de la economía moderna. Cualquier decisión de política basada en este concepto de un sistema complicado que es la suma de sus partes puede ser peligrosamente inexacta e inapropiada. ¿Cuáles son las fuerzas que impulsan esta complejidad creciente en la economía global? ¿Qué puede hacerse al respecto, si es que hay algo que pueda hacerse?

Un sistema complejo puede comprenderse en términos generales como una red de nodos, en la cual los nodos están interconectados en varios niveles a través de canales únicos o múltiples. Eso significa que lo que suceda en un nodo se transmite a través de la red y es probable que impacte en otros nodos en varios niveles. Por consiguiente, el comportamiento del sistema como un todo depende de los nodos, así como de la naturaleza de las conexiones entre ellos. La complejidad del sistema, en este caso, la economía global, está influenciada por varios factores: primero, el número de nodos; en segundo lugar, el número de interconexiones; 
tercero, la naturaleza de las interconexiones, y cuarto, la velocidad a la cual se propaga a otros nodos un estímulo o un choque. Ahora apliquemos cada uno de estos factores a la economía global.

El número de nodos de la economía global ha aumentado con rapidez. Una forma de comprender este suceso es observar a los países que participan activamente en la economía global. El crecimiento de China y de otros mercados emergentes, así como su integración creciente en el comercio mundial y, más recientemente, en los sistemas financieros globales, son un buen representante para seguir el incremento del número de nodos. El tamaño relativo y la importancia de estos nodos también han aumentado con la República Popular China, la economía más grande del mundo según algunos indicadores.

De manera simultánea, el número de interconexiones entre nodos ha crecido con aun mayor rapidez. El número de conexiones posibles entre nodos se incrementa de manera no lineal con el aumento del número de nodos, por lo que la economía global ahora tiene un número mayor de vínculos financieros, económicos, comerciales, de información, de políticas, institucionales, tecnológicos, militares, de viaje y humanos entre los nodos, como nunca antes. La creciente complejidad de las cadenas de suministro en el comercio y la producción, la cada vez mayor subcontratación de servicios, las colaboraciones militares en aumento, la naturaleza global de los nuevos avances tecnológicos, la creciente migración y el aumento de viajes, así como el aumento del tráfico en la Internet y las telecomunicaciones en todo el mundo han aumentado mucho el número de conexiones entre los nodos.

No se trata solo de que el número de interconexiones entre nodos haya aumentado casi exponencialmente. El alcance y la naturaleza de estos vínculos se han extendido de manera importante. Los ejemplos más notorios de esta ampliación han sido el rápido aumento de complejas cadenas de suministro de la producción, los vínculos financieros derivados directamente del desmantelamiento gradual de los controles de capital, y el aumento de las comunicaciones transfronterizas y la difusión de información a través de la Internet. Estas conexiones cada vez más extendidas entre diferentes nodos cambian fundamentalmente el comportamiento del sistema y la 
forma en la que la economía reacciona ante cualquier estímulo, cambio o choque en uno o más nodos en formas que se vuelven cada vez más difíciles de modelar o predecir.

Por último, pero no por eso menos importante, lo que ha aumentado no es solo el número y la intensidad de los vínculos entre los nodos, sino también la rapidez con la que la información, la tecnología, el conocimiento, los choques, las finanzas o los patógenos se mueven entre los nodos. El resultado, en la jerga de la teoría de la complejidad, es una economía global cada vez más estrechamente acoplada. Estos sistemas son más eficientes y la búsqueda de eficiencia ha dado lugar a cadenas de suministros justo a tiempo y al aumento en la velocidad de las operaciones financieras y otros acontecimientos. Pero esta eficiencia está acompañada de un incremento en la fragilidad. Cada vez es más evidente que los choques financieros, económicos, patogénicos y de seguridad, entre otros, se están expandiendo más rápidamente por el mundo.

En resumen, los modelos de equilibrio general dinámico estocástico (EGDE o DSGE, por sus siglas en inglés) y otros enfoques tradicionales que modelan la economía global reflejan de manera cada vez más inadecuada e inexacta la creciente complejidad de la economía global. Dicha complejidad ha sido impulsada tanto por el aumento del número de nodos (países) ahora integrados en la economía global, como por el número y la naturaleza de las interconexiones entre ellos, las cuales se intensifican a un ritmo cada vez más veloz.

Lo anterior requiere una nueva forma de abordar la formulación de políticas que incorpore enseñanzas de la teoría de la complejidad, utilizando un enfoque a nivel de todo el sistema para la modelización, que cambie el diseño institucional para reducir la fragilidad del sistema y que intensifique la formulación de políticas internacionales e intersectoriales, así como la coordinación de políticas.

\section{Enlaces útiles}

El artículo original sobre Esenciales OCDE, incluidos enlaces y material complementario, puede consultarse en: $h t t p: / / w p \cdot m e / p 2 v 60 D-2 A Y$

Consulte la serie completa en: http://oecdinsights.org/?s=NAEC+complexity 


\section{Complejidad económica, instituciones y desigualdad de ingresos}

por César Hidalgo y Dominik Hartmann, Macro Connections, The MIT Media Lab

¿La estructura de la productividad de un país determina su capacidad de generar y distribuir el ingreso? Hace varias décadas, Simon Kuznets propuso una relación con forma de U invertida que describía la conexión entre el nivel de ingreso promedio de un país y su nivel de desigualdad de ingresos. La curva de Kuznets sugería que la desigualdad de ingresos primero se elevaría y luego bajaría, a medida que el ingreso de los países se desplazara de abajo hacia arriba. Sin embargo, se ha comprobado que es difícil verificar empíricamente la curva. La función con forma de U invertida no se sostiene si se elimina de la muestra a varios países de América Latina $\mathrm{y}$, en décadas recientes, la parte superior de la curva de Kuznets desaparece debido a la desigualdad creciente en muchos países de bajos ingresos. Por otra parte, en varias economías de Asia Oriental los ingresos subieron de bajos a medios y se redujo la desigualdad en este ámbito.

En conjunto, estos resultados debilitan la solidez empírica de la curva de Kuznets, e indican que el PIB per cápita es una medida de desarrollo económico insuficiente para explicar las variaciones en la desigualdad de ingresos. Esto coincide con trabajos recientes en los que se afirma que la desigualdad no solo depende de la tasa o etapa de crecimiento de un país, sino también de su tipo de crecimiento y sus instituciones. Por consiguiente, es de esperar que medidas del desarrollo económico más diferenciadas, como las centradas en los tipos de productos que exporta un país, ofrezcan información sobre la conexión entre el desarrollo económico y la desigualdad que trasciende las limitaciones de las medidas agregadas de producción, como el PIB.

Los investigadores han manifestado que la desigualdad de ingresos depende de diversos elementos de una economía, desde su dotación de factores, sus características geográficas y sus instituciones, hasta su trayectoria histórica, sus cambios tecnológicos y sus retornos de capital. La combinación de estos factores debería 
expresarse en la mezcla de productos que fabrica un país. Por ejemplo, las economías coloniales que se especializan en un conjunto reducido de productos agrícolas o minerales tienden a tener una distribución más desigual de poder político, capital humano y riqueza. Por el contrario, los productos sofisticados, como dispositivos de imagenología médica o componentes electrónicos, son producidos normalmente en economías diversificadas que requieren más instituciones incluyentes. Las industrias complejas y las economías complejas prosperan cuando los trabajadores tienen la capacidad de hacer aportaciones creativas a las actividades de las empresas.

Lo anterior sugiere un modelo de industrias heterogéneas en el cual las empresas subsisten solo cuando son capaces de adoptar o descubrir las instituciones y el capital humano que mejor funcionan en esa industria. De acuerdo con este modelo, la mezcla de productos que exporta un país debería reflejar a sus instituciones y la calidad de su capital humano. Este modelo también sugeriría que la mezcla de productos de un país tendrá que ofrecer información que explique la desigualdad y que pueda evitar medidas agregadas de desarrollo como el PIB, el promedio de años de escolarización o aquellas basadas en estudios de instituciones formales e informales.

Con nuestros colegas del MIT Media Lab, usamos el Índice de Complejidad Económica (ICE) para registrar información sobre el nivel de desarrollo de una economía, el cual es distinto del registrado en indicadores de ingreso. La complejidad económica es una medida del conocimiento de una sociedad que se traduce en el producto que crea. Los productos más complejos son químicos y maquinaria sofisticados, en tanto que los menos complejos son materias primas o productos agrícolas sencillos. La complejidad económica de un país depende de la complejidad de los productos que exporta. Un país es considerado complejo si exporta no solo productos de alta complejidad, sino también un gran número de productos diferentes. Para calcular la complejidad económica de un país, medimos la ubicuidad promedio de los productos que exporta, después la diversidad promedio de los países que hacen esos productos, y así sucesivamente.

Por ejemplo, en 2012, el ingreso per cápita promedio y los años de escolarización de Chile (USD 21044 en Paridad del Poder Adquisitivo 
a dólares de 2012 y una media de 9.8 años de escolarización) eran comparables al ingreso per cápita y la escolarización de Malasia (USD 22314 y 9.5 años), aunque este último se ubicaba en el lugar 24 de la clasificación del ICE, mientras que Chile se encontraba en el lugar 72. Las clasificaciones reflejan las diferencias en la estructura de exportación de estos países: Chile exporta en gran medida recursos naturales, mientras que Malasia exporta una amplia gama de productos electrónicos y maquinaria. Además, estas diferencias en la clasificación del ICE también señalan de manera más precisa las diferencias en el nivel de desigualdad de ingresos de estos países. La desigualdad de Chile, medida con el coeficiente de Gini (0.49), es significativamente más alta que la de Malasia (0.39).

Separamos la correlación entre la complejidad económica y la desigualdad de ingresos de la correlación entre la desigualdad de ingresos y el ingreso promedio, la población, el capital humano (medido por el promedio de años de escolarización), la concentración de las exportaciones y las instituciones formales. Nuestros resultados sustentan una correlación fuerte y sólida entre el índice de complejidad económica y la desigualdad de ingresos. Esta relación es sólida aun después de tomar en cuenta medidas de ingreso, educación e instituciones, y la relación se ha mantenido fuerte durante los últimos 50 años. Los resultados también muestran que los incrementos en la complejidad económica tienden a acompañarse de reducciones en la desigualdad de ingresos.

Nuestros hallazgos no significan que únicamente las estructuras productivas determinan el nivel de desigualdad de ingresos de un país. Por el contrario, una explicación más probable es que las estructuras productivas representan una expresión de alta resolución de varios factores, desde instituciones hasta educación, que coevolucionan con la mezcla de productos que exporta un país y con el carácter incluyente de su economía. Sin embargo, debido a esta coevolución, nuestras conclusiones destacan que las estructuras productivas no solamente se relacionan con el ingreso y el crecimiento económico, sino también con la manera como se distribuye el ingreso.

Nosotros promovemos métodos que permitan una perspectiva más detallada de la relación entre las estructuras productivas y la desigualdad de ingresos. El método se basa en la instauración del 
Índice de Gini de Productos (PGI, por sus siglas en inglés), el cual calcula el nivel esperado de desigualdad de los países que exportan un determinado producto. Superponer los valores del PGI en la red de los productos relacionados nos permite crear mapas que puedan utilizarse para anticipar cómo los cambios en la estructura productiva de un país afectarán su nivel de desigualdad de ingresos. Estos mapas ofrecen medios para que los investigadores y los responsables de formular políticas exploren y comparen la compleja coevolución de estructuras productivas, instituciones y desigualdad de ingresos de cientos de economías.

\section{Enlaces útiles}

El artículo original sobre Esenciales OCDE, incluidos enlaces y material complementario, puede consultarse en: $h t t p: / / w p \cdot m e / p 2 v 60 D-2 C N$

Consulte la serie completa en: http://oecdinsights.org/?s=NAEC+complexity 


\section{Multitudes, consensos y complejidad en el pronóstico económico}

por Brian Dowd, FocusEconomics

Predecir el comportamiento futuro de cualquier cosa, especialmente de algo tan complejo y enorme como una economía entera, no es tarea fácil. Por consiguiente, los pronósticos precisos son escasos. Las economías son sistemas complejos en perpetuo movimiento y extrapolar los comportamientos y las relaciones de ciclos económicos anteriores al siguiente es tremendamente complicado. Además, y tal vez sorpresivamente, pronosticar es difícil debido a la enorme cantidad de datos económicos crudos disponibles. En un mundo ideal, los pronósticos económicos considerarían toda la información disponible. Sin embargo, en el mundo real esto es casi imposible, ya que la información está esparcida en un sinnúmero de artículos periodísticos, comunicaciones gubernamentales, y demás, así como en la montaña de datos crudos.

Si bien algunos consideran que tener toda esa información es ventajoso, nada podría estar más lejano de la verdad. Los miles de indicadores y datos disponibles tienden a producir una enorme cantidad de ruido estadístico, lo que provoca que entablar relaciones de causalidad significativas entre variables se convierta en un serio desafío. Y, por supuesto, no podemos olvidar la incertidumbre inherente al pronóstico, algo que los analistas deben considerar y que genera aún más ruido.

Cabe entonces preguntar, ¿hay alguna manera de anular todo ese ruido para obtener un pronóstico más preciso? Aquí entra en juego "la sabiduría de las masas". Sir Francis Galton, un erudito victoriano, fue el primero en darse cuenta de la sabiduría de las masas en una feria de ganado que visitó en 1906. Los asistentes tenían la oportunidad de adivinar el peso de un buey, y la mejor estimación ganaba un premio. Galton planteó la hipótesis de que ninguna persona por sí sola obtendría la respuesta correcta, sino que todos lo harían. No es tan contradictorio como suena. Más de 750 participantes hicieron sus suposiciones y, como era de esperarse, nadie adivinó el peso exacto. Sin embargo, cuando Galton calculó la 
media de todas las suposiciones, increíblemente, esta resultó ser el peso exacto del buey: 1198 libras.

La idea básica de la sabiduría de las masas es que el promedio de las respuestas de un grupo de individuos a menudo es más preciso que la respuesta de cualquier individuo por sí solo, como ocurrió en el experimento de Galton. La precisión de la sabiduría de las masas incrementa con el número de participantes y la diversidad de conocimientos expertos de cada participante individual.

Entonces, ¿qué tiene que ver la sabiduría de las masas con el pronóstico económico? ¿Recuerda todo ese ruido que dificulta tanto hacer un pronóstico económico y que afecta la precisión? La teoría es que el ruido idiosincrático está asociado con todas y cada una de las respuestas individuales y al tomar el promedio de las múltiples respuestas el ruido tiende a eliminarse a sí mismo, lo que presenta una imagen mucho más exacta.

También llamado a veces simplemente combinación de pronósticos, el pronóstico por consenso toma prestada la misma idea de la sabiduría de masas de Galton. Es básicamente el promedio de los pronósticos de varias fuentes. Gran parte de la investigación empírica de las últimas décadas muestra que promediar múltiples pronósticos elimina el ruido estadístico y genera un pronóstico mucho más preciso. Dicho esto, es posible que un pronóstico individual supere el consenso, pero no es probable que el mismo analista lo logre de manera consistente un periodo pronosticado tras otro. Además, es imposible elegir con anticipación estos pronósticos individuales que logran superar el consenso en un periodo, pues varían significativamente de uno a otro.

Un ejemplo práctico muestra las ventajas del pronóstico por consenso. El pronóstico por consenso del PIB de Malasia en 2015, realizado en enero de 2015 fue de 5.1\%. En marzo de 2016, la lectura real resultó 5.0\%. Como se esperaba, algunos pronósticos estuvieron más cerca del resultado final que el pronóstico por consenso pero, como se mencionó, sería imposible saber de cuáles de todos ellos se trata antes del hecho. Otra forma de considerarlo es comparar distintos pronósticos individuales con lo que en realidad sucedió, como lo hicimos con 25 pronósticos de analistas económicos del 
PIB de Malasia en 2015 en enero de ese mismo año. Ya en marzo de 2016, el pronóstico máximo de este grupo resultó $16 \%$ más alto que la lectura real, y el mínimo, 10\% más bajo. El consenso se ubicó apenas $1.9 \%$ por encima de la lectura real. Al tomar el promedio de todos los pronósticos, los errores hacia arriba o hacia abajo de cada uno de los diferentes pronósticos se eliminaron mutuamente en su mayoría. Como resultado, el pronóstico por consenso fue mucho más cercano a la lectura real que la mayoría de los pronósticos individuales.

Tanto si hay pronósticos por consenso como pronósticos individuales o de algún otro tipo, predecir el futuro casi nunca arrojará resultados exactos. En el ejemplo de Malasia, el consenso no fue certero, pero ciertamente redujo el margen de error. Casi siempre habrá algún error, pero reducirlo es la clave, y frecuentemente esto generará un pronóstico más preciso. El consenso no únicamente reduce el margen de error, también ofrece un poco de consistencia y veracidad. Los pronósticos de analistas individuales pueden variar de manera importante de uno a otro, mientras que el consenso constantemente ofrece pronósticos precisos.

Pronosticar es una ciencia, pero no es una ciencia exacta. Quizá no sean perfectos, pero los pronósticos siguen siendo muy importantes para las empresas y los gobiernos, pues arrojan luz sobre el futuro, y ayudan a tomar decisiones fundamentales sobre estrategias, planes y presupuestos. Entonces, ¿deberíamos confiar en los pronósticos? Cierto, pronosticar es complicado y sí, es bien sabido que los pronósticos son inexactos y hay pocas formas de mejorar su precisión de manera constante. Sin embargo, el punto es que para ser útiles no necesariamente tienen que ser perfectos, solamente tienen que ser lo más precisos posible. Una forma de lograrlo es aprovechar la sabiduría de las masas para que los analistas realicen un pronóstico por consenso.

Como señaló el matemático, físico y filósofo francés, Henri Poincaré, "es mucho mejor anticipar, aun sin certeza, que no anticipar nada". El pronóstico por consenso es una forma más precisa de "anticipar". 


\section{Enlaces útiles}

El artículo original sobre Esenciales OCDE, incluidos enlaces y material complementario, puede consultarse en: http://wp.me/p2v6oD-2Mn

Consulte la serie completa en: http://oecdinsights.org/?s=NAEC+complexity 



\section{Complejidad y sistema financiero}




\section{Un sistema financiero global complejo}

por Adrian Blundell-Wignall, Asesor especial del Secretario General de la OCDE sobre Asuntos Financieros y Empresariales

Las finanzas mundiales son el ejemplo perfecto de un sistema complejo, ya que consisten en un sistema altamente interconectado de subsistemas que presentan puntos de inflexión, emergencia o surgimiento, asimetrías, consecuencias involuntarias, una estructura de "partes dentro de partes" (citando a Herbert Simon) y todas las demás características que definen la complejidad. Están conformadas por numerosas tendencias y choques internos y externos en los que también influyen y a su vez generan. Y como el sistema (en casi todas partes) también reacciona a lo que se predice de él, puede denominarse sistema caótico "nivel dos" (como lo describe, por ejemplo, Yuval Harari).

Muchos acontecimientos se combinaron para contribuir a la crisis de 2008, y varios de ellos dieron como resultado estructuras que intervinieron de manera decisiva en la crisis fueron la apertura de las economías de la OCDE al comercio y la inversión internacionales después de 1945, y los rápidos avances de la tecnología y las redes digitales. Esas tendencias trajeron una mayor complejidad de productos financieros y estructuras requeridos para sortear este nuevo mundo, y fueron más allá de la necesidad de satisfacer el aumento de la demanda de servicios bancarios transfronterizos al incluir nuevos productos que facilitarían la cobertura de riesgos de tipo de cambio y de incumplimiento de pago de créditos; ingeniería financiera para cubrir los vencimientos requerida por ahorradores e inversionistas, y para tomar ventaja de los diferentes regímenes fiscales y regulatorios; fusiones y adquisiciones no únicamente de empresas, sino de la bolsa de valores y mercados relacionados con capacidades globales, y nuevas plataformas y adelantos tecnológicos para manejar el comercio de nuevos productos volátiles.

A la apertura de mercados de productos le siguió la liberación de los mercados financieros, la cual, en ciertos aspectos, fue su necesaria contraparte. Sin embargo, el proceso fue constante: para finales de la década de 1990, las políticas fomentaron el modelo de "supermercado financiero" y en 2004 las reglas sobre capitales 
bancarios se volvieron materialmente más favorables para el apalancamiento de la banca, como lo fueron las modificaciones a las reglas para la banca de inversión. El sistema bancario se convirtió en el epicentro de la crisis financiera mundial, debido a la infravaloración del riesgo, debido en esencia a la deficiente regulación microprudencial, el apalancamiento excesivo y los modelos de negocio demasiado grandes para quebrar. El surgimiento del inversionista institucional, la expansión del apalancamiento y los derivados financieros, la intensificación general de los mercados financieros y los avances tecnológicos generaron innovaciones no solo en los productos sino también en la forma de negociar los valores, por ejemplo, la negociación de alta frecuencia. La creciente separación de los propietarios de la dirección empresarial también agregó una nueva capa de complejidad, lo que agravó algunos de estos problemas (fondos pasivos, fondos cotizados en bolsa [ETF, por sus siglas en inglés], detención del agente de préstamos, rehipotecación, asesores y consultores forman parte de esta mezcla).

Las tendencias hacia la apertura de las economías de la OCDE no se reflejaron en las economías de mercados emergentes (EME) en general y en Asia en particular. Los controles de capital permanecieron fuertes en algunas EME a pesar de que el sistema financiero interno se ha fortalecido y está mejor regulado. Además, las medidas de control de capital a menudo apoyaron un régimen de tipo de cambio controlado en relación con el dólar estadounidense. Cuando los países intervienen para fijar sus divisas frente al dólar, adquieren dólares estadounidenses y normalmente los reciclan en tenencias de bonos del Tesoro de Estados Unidos, títulos muy líquidos y de bajo riesgo. Hay dos efectos importantes del tamaño cada vez mayor de las EME pertenecientes al "bloque del dólar": primero, reducen los rendimientos del Tesoro a medida que las reservas de sus bonos aumentan; segundo, su intervención en los mercados de divisas significa que la economía estadounidense enfrenta un desajuste en sus tipos de cambio en relación con sus socios comerciales.

Las tasas de interés bajas, junto con los rendimientos más reducidos de los valores del Tesoro, motivaron a los inversionistas a buscar productos de mayor riesgo y mayor rendimiento. En los periodos percibidos como "en riesgo", esto contribuye a aumentar la afluencia de créditos de alto rendimiento a las EME, la cual a su 
vez contribuye a una mayor intervención en los mercados de divisas y a un incremento de las medidas de control de capital. El peligro potencial es que en los periodos percibidos como "fuera de riesgo", el intento de vender estos activos no líquidos provocaría presiones enormes para el financiamiento de las EME y mucha volatilidad en los mercados financieros.

El euro también afecta la estabilidad financiera, a menudo de maneras inesperadas... Los países europeos negocian entre ellos y también con el resto del mundo. Sin embargo, a través de las cadenas globales de valor, el norte de Europa está integrado de manera más vertical en Asia, que experimenta un fuerte crecimiento debido a la demanda de tecnología de alta calidad, infraestructura y otros productos de inversión, en tanto que el sur de Europa compite con las EME en mayor grado en el comercio de manufacturas de menor nivel. Los choques asimétricos reales en diferentes regiones de la eurozona, como políticas fiscales divergentes o cambios en la competitividad de las EME, significan que un enfoque único a la política monetaria crea divergencias económicas. Los préstamos incobrables resultantes generan problemas de fragilidad financiera y la interconexión agravan la complejidad del problema.

El envejecimiento de la población se suma a estas preocupaciones, en particular debido a las interacciones entre una mayor esperanza de vida, los bajos rendimientos de los bonos gubernamentales que apuntalan los fondos para pensiones y la falta de ahorro de las personas con menor riqueza, a quienes la crisis afectó con mayor fuerza y que podrían sufrir por los futuros cambios en las estructuras de empleo y de trayectoria profesional. Para cumplir con los objetivos de rendimiento, las instituciones han asumido más riesgos en productos que a menudo son menos transparentes y donde los proveedores intentan crear una "liquidez artificial" que no existe en los valores y activos subyacentes.

Sin embargo, a pesar de la magnitud y complejidad del sistema financiero, este no es un fin en sí mismo. Su función debería ser ayudar a financiar el crecimiento económico y los empleos que contribuirán al bienestar. Pero, a pesar de todas las interconexiones, paradójicamente, como se sostiene en el OECD Business and Finance Outlook 2016 (Perspectivas de negocios y financieras de la OCDE 
2016), la fragmentación está bloqueando la inversión empresarial y el crecimiento de la productividad.

En los mercados financieros, la tecnología de la información y las reformas regulatorias allanaron el camino de la fragmentación con respecto a un mayor número de foros de negociación bursátil y crearon los llamados grupos de "negociación oscura". Las diferencias en los requerimientos regulatorios y la divulgación entre los foros de negociación crean preocupación respecto a la transparencia del mercado de valores y la igualdad de trato a los inversionistas. Además, las corporaciones pueden resultar negativamente afectadas si la velocidad y la complejidad se recompensan durante la inversión a largo plazo.

Los distintos regímenes legales entre los países y en la creciente red de tratados de inversión internacionales también fragmentan el entorno empresarial. Las leyes nacionales de diferentes países sancionan los sobornos extranjeros con un rigor desigual y a menudo insuficiente, y muchos tratados de inversión han creado reglas que pueden fragmentar a las compañías en lo que respecta a sus inversionistas y perturbar las normas establecidas sobre gobierno corporativo y finanzas corporativas.

La complejidad es parte de la naturaleza del sistema financiero, pero si queremos que este intervenga en el financiamiento del crecimiento incluyente y sostenible, necesitamos volver a unir estas piezas fragmentadas de una forma más armónica.

\section{Enlaces útiles}

El artículo original sobre Esenciales OCDE, incluidos enlaces y material complementario, puede consultarse en: $h t t p: / / w p \cdot m e / p 2 v 60 D-2 J C$

Consulte la serie completa en: http://oecdinsights.org/?s=NAEC+complexity 


\title{
La complejidad y una mejor regulación financiera
}

\author{
por Harald Stieber, Unidad de Análisis Económico y Evaluación, \\ DG FISMA, Comisión Europea
}

La crisis financiera de 2007-2008 no se debió solamente a la complejidad. Fue causada por el apalancamiento financiero que creció rápidamente hasta llegar a un punto de ruptura. Si bien la deuda mayoritariamente a corto plazo utilizada para el apalancamiento consiste de "contratos expuestos", era necesario detectar la ubicación precisa de ese punto de ruptura en el espacio y el tiempo reales y no en un entorno controlado de simulación. Asimismo, las complejas pautas dinámicas que surgieron a medida que se desarrollaba la crisis mostraron que poco se había aprendido sobre cómo transmitiría estrés un sistema financiero cada vez más complejo. La consecuente afectación de los mercados y la velocidad de la propagación del riesgo entre los diferentes mercados e infraestructuras de mercado no se conocían de antemano y tuvieron que descubrirse "sobre la marcha". Nuestro desconocimiento de estas propiedades estáticas y dinámicas del sistema refleja problemas arraigados vinculados con la gobernanza de datos, las capacidades de modelado y el diseño de políticas (en ese orden).

Desde una perspectiva de políticas públicas, la crisis reveló que varias partes del ecosistema financiero permanecieron fuera del perímetro regulatorio. Por consiguiente, ya no se proporcionaba el bien público de la estabilidad financiera en grado suficiente en todas las circunstancias. Sin embargo, la agenda regulatoria posterior, bajo un enfoque basado en principios coordinado a nivel del recién creado G20, en tanto que cerró muchas brechas regulatorias importantes, también creó una creciente complejidad en este ámbito.

La complejidad regulatoria también puede aumentar los riesgos para la estabilidad financiera. Un mayor costo de cumplimiento puede generar una conducta de evasión, que disminuye la eficacia de la regulación financiera pues muchas entidades y agentes regulados participarán en arbitraje regulatorio, así como en el intento de escapar del todo del perímetro regulatorio mediante la innovación financiera. Hasta fecha reciente, se consideró que por lo menos a las 
instituciones financieras más grandes les "agradaba" la complejidad regulatoria.

No obstante, la percepción de la complejidad en la industria financiera está cambiando. Ya no puede contemplarse a la complejidad como un costo de cumplimiento y el riesgo de que se impongan multas ha aumentado. Una de las declaraciones más claras en esta dirección se presentó en una carta de asociaciones de operaciones financieras que la Comisión Europea (junto con todos los principales reguladores) recibió el 11 de junio de 2015. En su carta, las asociaciones convocaban a una acción coordinada en el área de estándares financieros (datos) que reduciría la complejidad a un nivel que pudiera volver a ser manejado por el sector.

La agenda de Mejor Regulación de la Comisión Europea tiene como componente principal el principio de que es necesario evaluar las reglas existentes de manera continua, con el fin de valorar su eficacia ${ }^{1}$ y su eficiencia. ${ }^{2}$ Según dicha agenda, la Comisión emprendió una consulta pública en 2015 convocando a los actores interesados a aportar pruebas sobre 15 temas con un fuerte foco en el efecto acumulado de la regulación financiera en vigor. El objetivo era identificar posibles duplicaciones, inconsistencias, superposiciones o brechas en el marco regulatorio financiero cuya complejidad había aumentado considerablemente. El área de reporte (datos) surgió como un área relevante en la que las respuestas apuntaban a posibles ganancias futuras importantes en eficacia y eficiencia regulatorias.

El reporte regulatorio ha sufrido grandes cambios, al identificarse la falta de información pertinente a nivel de las autoridades supervisoras como una fuente importante de riesgo durante la crisis. En especial, la legislación en el área de mercados financieros, como el Reglamento sobre la Infraestructura del Mercado Europeo (EMIR, por sus siglas en inglés), pero también la Directiva sobre Mercados de Instrumentos Financieros (MiFID/R, por sus siglas en inglés) utilizó un enfoque diferente al reporte regulatorio en comparación

${ }^{1}$ Eficacia: ¿Corresponde el impacto observado en el terreno al resultado buscado por los colegisladores de la Unión Europea?

2 Eficiencia: ¿Se logra el resultado regulatorio deseado al menor costo de cumplimiento posible? 
con las obligaciones de reporte existentes para las instituciones financieras reguladas (por ejemplo, Common Reporting o COREP y Financial Reporting o FINREP). El Reglamento EMIR se centra en la transacción financiera individual (o derivados financieros negociados en mercados no regulados) y el reporte a nivel más detallado del contrato financiero individual. La presentación de reportes de conformidad con el EMIR empezó a desarrollarse en varias etapas a partir de febrero de 2014 y sigue en curso, empezando con los contratos más normalizados y continuando con los menos normalizados. Este enfoque se extiende a una clase más amplia de instrumentos en el marco del MiFID/R.

Este enfoque detallado al reporte regulatorio es muy prometedor desde la perspectiva de la ciencia de la complejidad. En algún punto podría facilitar delinear el ecosistema financiero de abajo arriba, así como propiciar el Desarrollo de un proceso de formulación de políticas de Global Systems Science. Sin embargo, para llegar a políticas más basadas en evidencias e impulsadas por la información, la gobernanza de datos y, más en concreto, los estándares de datos financieros, tendrán que adaptarse al cada vez más detallado entorno de reporte de datos.

La gobernanza de datos requiere estándares de datos financieros sólidos que se mantengan a la par del cambio tecnológico. Vemos algunas implicaciones precisas en esta etapa de lo que los estándares deberán hacer a este respecto. Los datos de contratos financieros son macrodatos. Los estándares de datos financieros generan pequeños datos a partir de macrodatos. Añaden estructura y escalabilidad en ambas direcciones.

Por tanto, en un proyecto de seguimiento al reclamo de evidencia buscamos distintas maneras en que los estándares de datos financieros y la tecnología regulatoria pueden ayudar a lograr objetivos de mejora regulatoria. Estas posibles maneras comprenden la definición de las metodologías de datos básicos, el desarrollo de modelos de puntos de datos, la exploración del uso de estándares algorítmicos, así como los posibles usos de las tecnologías de registros distribuidos y las tecnologías de consenso descentralizado. En esta etapa no podemos afirmar si la visión de un "sistema financiero libre" está a nuestro alcance en el mediano 
plazo. Pero las propiedades de resiliencia de la Internet representan una posible guía de cómo podría la tecnología ayudar al reporte regulatorio a alcanzar sus objetivos de manera mucho más potente en el futuro que al mismo tiempo reconozca la complejidad de nuestra materia.

\section{Enlaces útiles}

El artículo original sobre Esenciales OCDE, incluidos enlaces y material complementario, puede consultarse en: http://wp.me/p2v6oD-2B7

Consulte la serie completa en: http://oecdinsights.org/?s=NAEC+complexity 


\section{Modelos basados en agentes para contribuir a un mejor funcionamiento de la economía}

por Richard Bookstaber, Universidad de California

La economía no ha afrontado bien las crisis. En mi opinión, esto se debe a que hay cuatro características de la experiencia humana que se manifiestan en las crisis y que no pueden atenderse bien con los métodos de la economía tradicional.

La primera de dichas características es la irreducibilidad computacional. Quizá logremos reducir el comportamiento de un sistema sencillo a una descripción matemática que proporcione un atajo para predecir su conducta futura, de la misma manera como un mapa muestra que si se sigue un camino se llegará a una población sin tener que recorrer físicamente el camino antes. Por desgracia, en el caso de muchos sistemas, como sostiene Stephen Wolfram, uno solamente sabe lo que va a suceder si reproduce fielmente el camino que el sistema toma hasta su punto de llegada final, mediante la simulación y la observación, sin oportunidad de llegar al estado final antes que el propio sistema. Es algo parecido al mapa que Borges describe en On Rigor in Science, donde "el Mapa del Imperio tenía el tamaño del propio Imperio y coincidía con él punto por punto". No poder reducir la economía a un cálculo significa que no se tiene la capacidad de predecirla usando métodos analíticos, pero la economía exige que la tenga.

La segunda propiedad característica es la emergencia o surgimiento. Los fenómenos emergentes ocurren cuando el efecto general de las acciones de las personas es cualitativamente distinto de lo que cada uno de los individuos está haciendo. No es posible anticipar el resultado del sistema total con base en las acciones de sus miembros individuales porque el sistema grande tendrá propiedades que sus miembros individuales no tienen. Por ejemplo, el hecho de que algunas personas empujen a otras en medio de una multitud puede no tener consecuencias o puede generar una estampida en la que algunos resulten aplastados, aunque nadie lo desee o actúe intencionalmente para provocarlo. De igual manera, nadie decide provocar una crisis financiera y, de hecho, a nivel de las empresas individuales, por lo general se toman decisiones de 
emprender medidas prudentes para evitar los costosos efectos de una crisis. Pero lo que es localmente estable puede convertirse en algo globalmente inestable.

El nombre de la tercera característica, la no ergodicidad, proviene del físico alemán Ludwig Boltzmann, quien definió como "ergódico" un concepto de la mecánica estadística según el cual una sola trayectoria, continuada el tiempo suficiente a una energía constante, sería representativa de un sistema aislado en su conjunto (del griego ergon, energía, y odos, trayectoria). Los procesos mecánicos que impulsan nuestro mundo físico son ergódicos, al igual que muchos procesos biológicos. Podemos predecir cómo se moverá una bola al golpearla sin saber cómo llegó a su posición actual... el pasado no importa. Pero este pasado sí importa en los procesos sociales y no es posible sencillamente extrapolarlo para conocer el futuro. Por ejemplo, la dinámica de una crisis financiera no se refleja en el periodo previo a esta, porque los mercados financieros innovan de manera constante, de modo que el futuro quizá no se parezca en nada al pasado.

La incertidumbre radical completa nuestro cuarteto. Describe las sorpresas - resultados o eventos no anticipados-que no pueden incorporarse en una ley de probabilidad porque son ajenas a nuestra lista de cosas que podrían ocurrir. La energía eléctrica, la bomba atómica o la Internet son ejemplos del pasado y, por supuesto, por definición no sabemos cómo será el futuro. Como dijera Keynes, "No hay una base científica para formar ninguna probabilidad calculable en absoluto. Sencillamente, no sabemos". Los economistas hablan también de la "incertidumbre knightiana", después de que Frank Knight, quien distinguió entre el riesgo (por ejemplo, jugar en un casino donde no conocemos el resultado, pero podemos calcular las probabilidades) y lo que él llamó "incertidumbre verdadera" (donde no podemos saber todo lo que se requeriría para calcular las probabilidades). Esto, de hecho, es la condición humana. No sabemos a dónde vamos y no sabemos quiénes seremos cuándo lleguemos ahí. La realidad de la humanidad significa que un enfoque mecánico a la economía fracasará.

Entonces ¿hay alguna esperanza de entender lo que sucede en nuestra economía irreducible, emergente, no ergódica, y 
radicalmente incierta? Sí, si utilizamos métodos que sean más sólidos, que no estén incorporados en las expectativas racionales estándar, el modo de optimización de la economía. Para afrontar con éxito la crisis, necesitamos métodos que afronten la irreducibilidad computacional; que reconozcan la emergencia; que tomen en cuenta el hecho de que ni siquiera el presente se refleja en el pasado, mucho menos el futuro; y que puedan afrontar con éxito la incertidumbre radical. El modelado basado en agentes podría ser un paso en la dirección correcta.

Los modelos basados en agentes (ABM, por sus siglas en inglés) utilizan un sistema dinámico de agentes autónomos que interactúan para permitir que de reglas microscópicas emerja la conducta macroscópica. Los modelos especifican reglas que dictan cómo actuarán los agentes a partir de varias aportaciones. Cada agente, de manera individual, evalúa su situación y toma decisiones con base en sus reglas. Un buen ejemplo son los estorninos arremolinados en el cielo (en lo que se conoce como "murmuración"). Los pájaros parecen operar como un sistema y, sin embargo, el vuelo se basa en las decisiones que toman de manera individual. Construir un modelo macro descendente no reflejará la realidad de la situación, porque a nivel macro los movimientos de la bandada son complejos, no lineales, pero no basados en ningún programa aplicable a todo el sistema. Sin embargo, es posible modelar la murmuración fundamentándose en reglas sencillas respecto a cómo un pájaro reacciona a la distancia, la velocidad y la dirección de los demás pájaros y se dirige al centro percibido de la bandada en sus alrededores inmediatos.

De igual forma, el enfoque basado en agentes reconoce que los individuos interactúan y al interactuar cambian el entorno, lo cual conduce al próximo paso de interacción. Opera sin la ficción de un consumidor o inversionista representativo que está tan infaliblemente en lo correcto, como lo soñaría un modelo matemático. Permiten la construcción de una narrativa - singular y única para las circunstancias particulares del mundo real-en la que el sistema puede saltar las vías y deslizarse hacia abajo por la ladera de la montaña. Esta narrativa nos da la oportunidad de devolver el sistema a su punto inicial con seguridad. 
En resumen, la economía basada en agentes llega dispuesta a enfrentar al mundo real, el mundo que se amplifica y distorsiona en épocas de crisis. Se trata de un nuevo paradigma enraizado en el pragmatismo y en las complejidades de ser humano.

\section{Enlaces útiles}

El artículo original sobre Esenciales OCDE, incluidos enlaces y material complementario, puede consultarse en: http://wp.me/p2v6oD-2MX

Consulte la serie completa en: http://oecdinsights.org/?s=NAEC+complexity 

Aplicaciones de la teoría

de la complejidad 


\section{Urbanización y sistemas complejos}

por Colin Harrison, Distinguido Ingeniero Emérito IBM (retirado), antes encabezó el Desarrollo de Estrategia Técnica para la Iniciativa de IBM

La ciudad es el invento más grande de la Humanidad. Un ecosistema artificial que permite a millones de personas vivir en estrecha cercanía y colaborar en la creación de nuevas formas de valor. Si bien las ciudades se inventaron hace muchos milenios, su importancia económica ha aumentado drásticamente desde la Revolución Industrial, hasta representar ahora la fracción más importante de la economía mundial. Toda la vida humana está ahí y, por tanto, el estudio de las ciudades cruza fronteras entre la economía, las finanzas, la ingeniería, la ecología, la sociología, la antropología, y, digamos, casi todas las formas de conocimiento. No obstante, aunque tenemos más conocimientos en cada uno de estos campos en lo individual, tenemos poco conocimiento científico de cómo se agruparán en ese sistema general de sistemas que es una ciudad. En pocas palabras: ¿cómo funciona una ciudad?

Dicho conocimiento será útil en las próximas décadas. En los últimos 60 a 70 años, la globalización difundió con mucha mayor amplitud la Revolución Industrial, creando en las ciudades nuevas oportunidades que atraen a cientos de millones de migrantes nacionales e internacionales. El proceso está sacando a muchos de estos migrantes de la pobreza extrema, y a la vez ocasiona que las ciudades, desde Londres hasta Nairobi, batallen en diferentes maneras con la afluencia interminable de migrantes.

Además, las ciudades son responsables de grandes fracciones de emisiones de gases de efecto invernadero, del consumo de recursos naturales como el agua y el aire y de las descargas derivadas de contaminación al medio ambiente. Si se desea ganar la batalla contra el cambio climático, esta tendrá que ganarse en las ciudades. Las ciudades son también los principales centros para la innovación y el desarrollo económico, ambos necesarios para continuar sacando a los migrantes de la pobreza. 
Si bien las raíces de la planificación urbana se remontan a más de 3000 años atrás en términos de los planes maestros de las ciudades, fue el tremendo crecimiento de estas a finales del siglo XIX el que transformó este campo para considerar los muchos servicios y prestaciones que se requieren para los habitantes urbanos. Pero la planificación urbana emergió sobre todo de las humanidades y trabaja principalmente mediante extensos estudios de caso, aunque ha adoptado muchas herramientas digitales. El concepto de la ciudad como objeto de estudio científico es más reciente y aún se encuentra en sus etapas iniciales, impulsado en parte por los avances en la teoría de la complejidad, como la teoría de redes, las leyes de escalamiento y la ciencia de sistema, así como la creciente disponibilidad de datos urbanos.

Las leyes de escalamiento se han explorado por lo menos desde principios del siglo $\mathrm{XX}$, cuando se consideraba que las ciudades eran un ejemplo. En este caso la Ley de Zipf establece que "En la mayoría de los países, el número de ciudades con una población mayor de $S$ es proporcional a $1 / S^{\prime \prime}$. En años recientes se ampliaron en gran medida los conocimientos sobre el escalamiento gracias al trabajo de West y Bettencourt y Batty. Su obra mostró que muchas propiedades de las ciudades, como el número o la longitud de las calles, el número de prestadores de servicios como los restaurantes, entre otros, siguen leyes de escalamiento en grupos demográficos de 10 mil a decenas de millones de habitantes. Además, estas leyes de escalamiento tienen exponentes en rangos de 0.85 a 1.15 que muestran que las grandes ciudades son más productivas, innovadoras, eficientes en consumo de energía y caras que las ciudades pequeñas, pero que también pagan mejor que estas. De igual manera, atributos negativos como delincuencia, enfermedades y contaminación también escalan de manera superlineal, es decir, no se incrementan en proporción estricta al aumento del tamaño de la ciudad. Por ejemplo, el PIB es proporcional al Tamaño (S) de la ciudad elevado a una potencia que es ligeramente mayor que 1 -por consiguiente, $\mathrm{S}^{1.15}$-, en tanto que otros atributos como el consumo de energía per cápita escalan sublinealmente, para situarse en $S^{0.85}$. Las leyes de redes también describen bien la evolución a lo largo de escalas prolongadas de autopistas y vías férreas en ciudades. 
Si bien las leyes de escalamiento y las leyes de redes tienen un gran poder descriptivo, las opiniones varían en torno a si aplican a diferentes países o si tienen poder predictivo. Es decir, el escalamiento de atributos es una fotografía de la frecuencia frente al tamaño en cualquier momento. Si una ciudad crece y "asciende por la escala", quizá no logre, en el corto plazo, todos los beneficios (positivos) y los impactos negativos descritos. Tampoco las leyes ofrecen explicaciones de las conductas observadas. No obstante, esta es un área importante para los planificadores y desarrolladores que observan que sus ciudades crecen o se reducen.

A medida que los datos urbanos se han generalizado, ahora es posible estudiar a las ciudades como sistemas complejos de interacciones. Podemos considerar a la ciudad como una miríada de interacciones entre sus habitantes, su infraestructura y sus servicios, su entorno natural y sus organizaciones públicas, privadas y civiles. Algunas de estas interacciones implican el intercambio de bienes o servicios por dinero, pero muchas implican el intercambio o transmisión de información, que permite a los habitantes y las organizaciones hacer elecciones. El transporte público suele estudiarse de esta manera, que, por ejemplo, revela que las ciudades pequeñas y medianas desarrollan redes que permiten trasladarse entre pequeños números de distritos residenciales y de negocios, en tanto que las ciudades muy grandes, como Londres, tienen redes mucho más ricas que permiten tener mayor flexibilidad respecto al sitio donde las personas viven y trabajan.

La operación de las ciudades también se modela utilizando poblaciones sintéticas de agentes de software que representan la distribución de conductas o preferencias de poblaciones reales mucho más grandes. Dichos modelos basados en agentes, con agentes que representan patrones de origen, destino, horarios de viaje y preferencias de modalidad, se utilizan para examinar el impacto general ejercido por servicios nuevos, como el Crossrail de Londres.

Puesto que la Internet de las Cosas aporta mayor visibilidad de la manera como los habitantes eligen explotar las oportunidades ofrecidas por una ciudad determinada, podemos esperar descubrir principios abstractos sobre la manera en que las ciudades funcionan. 
Podemos visualizar tener la capacidad de construir modelos basados en agentes que representan el espectro completo de las elecciones que hacen los habitantes de una ciudad en escalas de tiempo que abarcan de minutos a años y escalas espaciales que abarcan de metros a kilómetros. De igual forma, dada la creciente disponibilidad de información en tiempo real, podríamos un día esperar comprender el uso eficaz de los servicios de una ciudad en términos del Equilibrio de Nash, un concepto de la teoría de juegos (usado a menudo para describir juegos de póker) en el que ningún jugador puede ganar nada al cambiar su estrategia elegida si otros jugadores no cambian la suya: todas las estrategias de los jugadores son óptimas. Hablamos en términos de un futuro lejano, pero el programa de Ciencia de Sistemas Mundial de la Comisión Europea es el principio del camino.

\section{Enlaces útiles}

El artículo original sobre Esenciales OCDE, incluidos enlaces y material complementario, puede consultarse en: $h t t p: / / w p \cdot m e / p 2 v 60 D-2 C x$

Consulte la serie completa en: $h t t p: / / o e c d i n s i g h t s . o r g / ? s=N A E C+$ complexity 


\title{
Macrodatos, teoría de la complejidad y desarrollo urbano
}

\author{
por Ricardo Herranz, Director Ejecutivo, Nommon Solutions \\ and Technologies, Madrid
}

Vivimos en la era de las ciudades: más de 50\% de la población mundial vive ya en zonas urbanas y la mayoría de las previsiones indican que, hacia finales de este siglo, la población mundial será casi por completo urbana. En este contexto, surge la visión de que los retos mundiales de erradicación de la pobreza, sostenibilidad ambiental, cambio climático y energía sostenible y segura están todos estrechamente ligados a las ciudades, que son sitios donde surgen estos problemas globales y a la vez se encuentra cómo solucionarlos. En el corto plazo, las ciudades enfrentan el gran reto de superar la crisis financiera y económica y emerger más fuerte de ella. En el largo plazo, necesitan afrontar retos estructurales relacionados con la globalización, el cambio climático, la presión sobre los recursos, el cambio demográfico, la migración y la segregación y polarización sociales. Muchos de estos retos son compartidos por ciudades de países desarrollados y en desarrollo, en tanto que otros dependen de diferencias geográficas, institucionales, socioeconómicas y culturales.

Al afrontar estos problemas, los responsables de formular políticas públicas y la sociedad enfrentan muchos que son fundamentales. Los múltiples componentes del sistema urbano están fuertemente entrelazados, lo cual genera una dinámica compleja y dificulta anticipar el impacto y las consecuencias involuntarias de la acción pública. Las ciudades no son sistemas cerrados, sino que forman parte de sistemas de ciudades. Las políticas de desarrollo urbano están sujetas a procesos de decisión multinivel y ejercen un profundo efecto sobre una amplia variedad de actores interesados, a menudo con objetivos opuestos o contradictorios.

En los últimos años hemos visto surgir conceptos como el de ciudad inteligente, informática urbanística, análisis urbanístico y ciencia ciudadana, que se consideran muy prometedores para mejorar el funcionamiento de las ciudades. Sin embargo, cabe afirmar que la mayor parte de este potencial aún está por lograrse. El 
concepto de la ciudad inteligente se acuñó a manera de una fusión de ideas sobre cómo las tecnologías de la información y la comunicación pueden ayudar a resolver problemas decisivos relacionados con las ciudades. Para este concepto resulta esencial la idea de un enfoque integrado a las sinergias y compensaciones entre diferentes campos de política que están estrechamente interrelacionados, pero que tradicionalmente se han abordado por separado, como el uso de suelo, el transporte y la energía. Este enfoque integrado se facilitaría con la capacidad de analizar los cada vez mayores flujos de datos generados por la omnipresente concienciación de las zonas edificadas y el uso generalizado de dispositivos móviles personales. En paralelo, los dispositivos inteligentes y las redes sociales también producen nuevas formas de participación pública en la planificación urbana. Las oportunidades son muchas, pero también son muchos los retos.

Se ha puesto mucha esperanza en la explosión de macrodatos para establecer los cimientos de una nueva ciencia de ciudades. Durante los últimos 20 años, la tendencia dominante en el modelado urbano cambió de modelos de equilibrio agregados a modelos dinámicos ascendentes (modelos basados en actividades y modelos basados en agentes) que buscan representar a las ciudades en términos más desglosados y heterogéneos. Esta creciente sofisticación del modelo acompaña a la necesidad de contar con datos abundantes y detallados para calibrar y validar los modelos, lo cual entorpece el uso operativo de enfoques de modelaje de vanguardia. El surgimiento de nuevas fuentes de macrodatos facilita la recopilación de datos espaciotemporales sobre la actividad urbana con un nivel sin precedente de detalles, lo cual nos brinda información que no estaba disponible en encuestas o datos obtenidos en censos. Esto ha arrojado ya importantes adelantos prácticos en campos como la planificación del transporte, pero es más cuestionable, por lo menos por ahora, que los macrodatos han generado avances considerables en nuestro conocimiento de las ciudades. En principio, el potencial existe: en tanto que la investigación sobre las ciudades ha dependido históricamente de conjuntos de datos demográficos y económicos intersectoriales, que a menudo consisten en muestras relativamente pequeñas, ahora tenemos datos longitudinales detallados a gran escala que pueden permitirnos poner a prueba nuevas hipótesis sobre la estructura y la dinámica urbanas. Por otra parte, se corre 
el riesgo de que los macrodatos generen un cambio de foco hacia modelos a corto plazo, predictivos y no aclaratorios, dejando a un lado la teoría. Conectar a la ciudad inteligente y a los movimientos de macrodatos con el conocimiento desarrollado en las últimas décadas en campos como la ciencia regional, la economía urbana y el modelado de transporte, aparece como condición esencial para superar este problema y aprovechar las oportunidades ofrecidas por los macrodatos para la formulación de mejores teorías y enfoques de política.

Tanto el trabajo empírico como los adelantos teóricos son necesarios para lidiar con los nuevos retos derivados de la escasez de energía y el cambio climático, de tecnologías emergentes como los automóviles de conducción autónoma y los cambios en las relaciones sociales, las nuevas actividades y las nuevas formas de compartir la economía, habilitados por las redes sociales y las comunicaciones electrónicas, entre otros factores que conducen a cambios profundos en la estructura y la dinámica urbanas. Igualmente difícil es integrar los datos y los modelos en procesos de gobernanza: la evaluación de políticas públicas y la planificación participativa aún se basan en gran medida en consideraciones cualitativas, y se tiene la sensación de que los modelos urbanos vanguardistas son inmaduros respecto de la integración institucional y el uso operativo. Nuevas formas de compartir y visualizar datos, de participación digitaly de participación ciudadana, son herramientas prometedoras para abordar este tema, pero, de nuevo, en este caso aún tenemos que dilucidar cómo compartir datos y conocimientos especializados en una forma que entrecruce procesos participativos de toma de decisiones y cierre la brecha entre el conocimiento implícito y el explícito. Los recientes avances en áreas como la teoría de redes, el modelado computacional basado en agentes y la teoría de decisión grupal y, de manera más general, el enfoque intrínsecamente holístico y ecléctico defendido por la ciencia de la complejidad, parecen ser un marco adecuado para el desarrollo de una nueva ciencia de ciudades que, a su vez, puede conducir a nuevos avances en la manera como las ciudades se planifican y gestionan, lo que nos permitirá atender los enormes retos relacionados con el desarrollo urbano en el siglo XXI. 


\section{Enlaces útiles}

El artículo original sobre Esenciales OCDE, incluidos enlaces y material complementario, puede consultarse en: http://wp.me/p2v6oD-2Di

Consulte la serie completa en: http://oecdinsights.org/?s=NAEC+complexity 


\section{Innovación y complejidad}

por Andrew Wyckoff, Director, Directorado de Ciencia, Tecnología e Innovación de la OCDE

Desde su creación en 1961, la OCDE ha influido en la manera en que los gobiernos enfocan la ciencia, la tecnología y la innovación y en que la economía, como disciplina, intenta entender estos fenómenos. En 1962 se estableció el Grupo de Trabajo de Expertos Nacionales en Indicadores de Ciencia y Tecnología (NESTI) de la OCDE y en 1963, el informe Science, economic growth and government policy (Ciencia, crecimiento económico y política gubernamental) convenció a los gobiernos de que la política de ciencias debería vincularse con la política económica. En 1971, el informe Science, growth and society (Ciencia, crecimiento y sociedad), también llamado el Informe Brook por el presidente del grupo, Harvet Brooks, anticipó muchas de las inquietudes actuales al hacer hincapié en la necesidad de involucrar a los ciudadanos en la evaluación de las consecuencias de desarrollar y utilizar nuevas tecnologías.

Sin embargo, para muchos expertos, la principal contribución fue el concepto de los sistemas nacionales de innovación, presentado en 1992 en una publicación emblemática, Technology and the Economy: The Key Relationships (Tecnología y la economía: las relaciones clave). Los orígenes del concepto se remontan a la crisis de 1970, la cual había provocado una reconsideración profunda del pensamiento económico anterior sobre cómo se lograba el crecimiento y por qué el crecimiento en productividad estaba en desaceleración. El informe de 1980, Technical Change and Economic Policy (Cambio técnico y política económica), es ahora ampliamente reconocido como el primer gran documento de política en cuestionar las interpretaciones macroeconómicas de la crisis de 1970 y en hacer hincapié en el papel de los factores tecnológicos para encontrar soluciones, argumentando, por ejemplo, que la innovación puede ser más poderosa que la competitividad salarial para estimular una economía.

Los economistas que trabajaban en la OCDE fueron los pioneros de un nuevo enfoque que contemplaba a la innovación no como un ente lineal sino como un ecosistema que implicaba interacciones 
entre el conocimiento, la investigación y la invención existentes; los mercados potenciales, y los procesos de producción. En las estrategias nacionales de innovación, uno de los temas clave lo constituyen las interacciones entre los diferentes actores: empresas, instituciones de investigación pública, organizaciones intermediarias, y así sucesivamente. Y, en oposición al pensamiento dominante en los círculos de las políticas públicas en la década de 1980 y principios de la de 1990, la OCDE también la consideraba como un elemento en el que los gobiernos debían desempeñar un papel central... de ahí el término estrategia nacional de innovación.

Hoy, los servicios se están convirtiendo en el foco de interés de la innovación y algunas empresas incluso desdibujan la distinción entre el valor agregado de productos y servicios y un ejemplo de ello son los teléfonos inteligentes. Este es un resultado lógico de la creciente digitalización de la economía. Las tecnologías digitales son ahora tan omnipresentes que es fácil olvidar cuán recientes son. Por ejemplo, la World Wide Web, la red mundial que conocemos ahora, se creó en la década de 1990 y Microsoft pensó que era posible lanzar una rival de la Internet (llamada MSN) en una fecha tan reciente como 1995. Google apenas se fundó en 1998 y no fue sino hasta seis años después que se hizo público.

Habiendo avanzado la economía y la sociedad digitales tanto en tan poco tiempo, es difícil predecir cómo serán en el futuro. Sin embargo, podemos identificar algunos impulsores del cambio. Los macrodatos serán de los más importantes. En The phenomenon of data-driven innovation (El fenómeno de la innovación impulsada por los datos), la OCDE cita cifras que sugieren que cada día se generan más de 2.5 exabytes (EB, mil millones de gigabytes) de datos, cantidad equivalente a 167000 veces la información contenida en todos los libros de la Biblioteca del Congreso de Estados Unidos. La empresa minorista más grande del mundo, Walmart, ya realiza más de un millón de transacciones de clientes cada hora. Debido a que se dispone de tantos nuevos datos, será posible desarrollar nuevos modelos que exploten el poder de un enfoque de complejidad para mejorar el conocimiento en las ciencias sociales, incluida la economía. Asimismo, el proceso de formulación de políticas puede beneficiarse de nuevas maneras de recabar información sobre las 
propias políticas y mejorar en gran medida nuestras competencias de evaluación.

El análisis de datos (a menudo en tiempo real), cada vez más de dispositivos inteligentes incorporados en la Internet de las Cosas, abre nuevas oportunidades para crear valor mediante la optimización de los procesos de producción y la creación de nuevos servicios. Esta "Internet industrial" está creando sus propios sistemas complejos, empoderando a máquinas y redes autónomas que pueden aprender y tomar decisiones independientemente de la participación humana. Esto puede generar nuevos productos y mercados, pero también crear caos en los mercados existentes, como lo han demostrado varias crisis financieras precipitadas.

Es necesario que los responsables de formular políticas públicas atiendan dos conjuntos de retos, o tensiones, para maximizar los beneficios de la innovación impulsada por la digitalización, y mitigar los riesgos económicos y sociales relacionados. El primero es promover la "apertura" del ecosistema mundial de datos y, por consiguiente, el libre flujo de información entre naciones, sectores y organizaciones, y, a la vez, atender los intereses opuestos de las personas y las organizaciones (en particular protegiendo su privacidad y su propiedad intelectual). El segundo conjunto de tensiones requiere encontrar políticas que activen a los facilitadores de la innovación impulsada por la digitalización, y a la vez atender los efectos de la "destrucción creativa" inducida por esta innovación. Además, hay una interrogante respecto a la eficacia de las políticas nacionales, pues la innovación impulsada por la digitalización es mundial por definición. Como responsable de la formulación de políticas públicas, usted puede promover algo en su país, pero los efectos indirectos en términos de empleo o de mercados pueden ubicarse en otros sitios.

Con la introducción de tantas nuevas tecnologías, con la integración de más empresas y países en las cadenas globales de valor y con el mayor nivel educativo que van adquiriendo los trabajadores en todas partes, podría esperarse que el crecimiento de la productividad estuviera en auge. De hecho, está en proceso de desaceleración. Pero esa tendencia promedio oculta la verdad, según se sostiene en un estudio de la OCDE sobre The Future of Productivity 
(El futuro de la productividad). La productividad laboral en las empresas más productivas a nivel mundial (empresas de la "frontera global") crecieron a una tasa anual promedio de 3.5\% en el sector de manufactura durante la década de 2000, en comparación con $0.5 \%$ de las empresas no ubicadas en esa frontera.

El saber hacer de las empresas fronterizas pioneras aún no se difunde al grueso de la economía, bien sea porque los canales están bloqueados o porque se encuentran en un periodo transformador y los conocimientos expertos sobre cómo explotar mejor las tecnologías todavía se encuentran en la mente de unos cuantos. Lo más probable es que ambas posibilidades estén combinadas. Por consiguiente, tenemos que ayudar a las empresas de la frontera global a seguir innovando y facilitar la difusión de nuevas tecnologías e innovaciones de las empresas de la frontera global a las empresas de la frontera nacional. Podemos intentar crear un entorno de mercado en el que se propicie que las empresas más productivas prosperen, facilitando con ello una penetración más amplia de las tecnologías y las innovaciones disponibles. Y debemos mejorar el ajuste de las competencias a los empleos para utilizar de mejor manera la reserva de talento disponible en la economía, y permitir que las personas competentes cambien de empleo y difundan el saber hacer a medida que se desplazan.

En un sistema complejo no es posible pronosticar los resultados con un grado relativamente alto de certidumbre, pero muchos de los resultados involuntarios de las interacciones en el sistema de innovación son benéficos. Cada una de las políticas antes mencionadas sería útil por sí sola y se espera que todas se reforzarían mutua y provechosamente.

\section{Enlaces útiles}

El artículo original sobre Esenciales OCDE, incluidos enlaces y material complementario, puede consultarse en: $h t t p: / / w p . m e / p 2 v 60 D-2 F f$

Consulte la serie completa en: http://oecdinsights.org/?s=NAEC+complexity 


\title{
Gobernanza de la educación en un mundo complejo
}

\author{
por Tracey Burns, Líder de Proyecto, Dirección de Educación \\ y Competencias de la OCDE
}

El famoso lema KISS (Keep it simple, stupid!) insta a quienes lo escuchan a mantener las cosas sencillas, directas; en pocas palabras, les dice que menos es más. Sin embargo, en la formulación de políticas modernas se aprecia cada vez más que no mantener las cosas sencillas - de hecho, optar por lo complejo- es esencial para entender los sistemas contemporáneos y hacer que las reformas funcionen.

Las sociedades modernas están compuestas de un número creciente de actores interesados diversos que colaboran a través de canales formales e informales. Los rápidos adelantos y el alcance de las tecnologías de la información y la comunicación les han permitido desempeñar un papel mucho más inmediato en la toma de decisiones, en tanto que la prestación de servicios públicos se ha descentralizado más.

Esta complejidad trae consigo una serie de dinámicas que el ciclo tradicional de política no refleja del todo. Esto no es de sorprender: numerosas críticas han descrito la ineficacia del ciclo de política tradicional en los campos de la agricultura, la medicina y la educación durante los últimos 30 años. Sin embargo, lo que ha cambiado es que un conjunto mucho más amplio de actores entiende cada vez más que no podemos continuar funcionando con modelos lineales tradicionales de reformas.

No se trata exclusivamente de un debate teórico: ignorar el carácter dinámico del proceso de gobernanza disminuye la eficacia de las reformas. Por ejemplo, en educación, incluso las escuelas que son muy similares entre sí pueden reaccionar de manera bastante distinta ante la misma intervención. Un estudio de caso realizado en los Países Bajos demostró que a algunas escuelas deficientes se les benefició con la calificación "Con necesidad de mejorar" al aglutinarse como comunidad escolar para activar un círculo virtuoso orientado a mejorar el desempeño. En cambio, otras escuelas tuvieron problemas al enfrentarse con la misma calificación y algunas entraron en un 
círculo vicioso: los profesores se sintieron desmotivados, los padres cambiaron a sus hijos a otra escuela y el rendimiento general bajó. Un modelo sencillo de reforma y gobernanza no puede dar cuenta de esta complejidad.

¿Cómo identificar la complejidad? En un trascendental artículo de 2002, Glouberman y Zimmermann distinguen entre tres tipos de problemas: los sencillos, los complicados y los complejos. Un problema sencillo, por ejemplo, es hornear un pastel. Para quien lo va a hacer por primera vez, la tarea no es sencilla, pero si tiene la receta y los ingredientes, puede confiar relativamente en que lo logrará. En este caso, tener conocimientos expertos ayuda, pero no es indispensable.

Por otro lado, un problema complicado sería enviar un cohete a la Luna. En este caso resulta esencial contar con fórmulas y tener conocimientos expertos de alto nivel no solo es útil, sino necesario. Sin embargo, los cohetes son semejantes entre sí en formas decisivas y, una vez que resuelva el problema complicado original, podrá estar razonablemente seguro de que será capaz de hacerlo de nuevo.

Tanto los problemas sencillos como los complicados pueden compararse con uno complejo, como educar a un hijo. Como todo padre de familia sabe, no hay una receta o fórmula que garantice el éxito en esta tarea. Educar a un hijo ofrece una experiencia útil, pero no es garantía de éxito con otro hijo. La razón es que cada niño es único y algunas veces, impredecible. Las soluciones que pueden funcionar en un caso quizá solamente funcionen de manera parcial o no funcionen en absoluto en otro caso.

De vuelta al ejemplo de la escuela deficiente, lo que hacía que el problema fuera complejo - y no solo complicado- era la imprevisibilidad de la dinámica intrínseca a la respuesta de las escuelas y sus comunidades. Reconocer la complejidad inherente a la gobernanza moderna es, por tanto, un primer paso esencial para una reforma eficaz.

Gobernanza moderna exitosa:

Secentra en los procesos, no en las estructuras. Casi todas las estructuras de gobernanza pueden tener éxito bajo las condiciones correctas. 
El número de niveles y el poder de cada uno no es lo que hace o quebranta a un buen sistema. Más bien, es la fuerza de la consonancia entre todo el sistema, la participación de los actores y los procesos subyacentes a la gobernanza y a la reforma.

$>$ Es flexible y tiene la capacidad de adaptarse al cambio y a los eventos inesperados. El fortalecimiento de la capacidad de un sistema de aprender de la retroalimentación es parte fundamental de este proceso y es también un paso necesario para el aseguramiento de la calidad y la rendición de cuentas.

> Funciona mediante el desarrollo de capacidad, la participación de los actores y el diálogo abierto. Sin embargo, no avanza sin timón: la participación de un rango más amplio de partes interesadas solo funcionará si se dispone de una visión estratégica y un conjunto de procesos para aprovechar sus ideas y sus aportaciones.

$>$ Requiere un enfoque a nivel de todo el sistema. Ello exige armonizar políticas, funciones y responsabilidades para mejorar la eficiencia y reducir la posibilidad de duplicación o conflicto (por ejemplo, entre la rendición de cuentas y la confianza o entre la innovación y la prevención de riesgos).

> Aprovecha la evidencia y la investigación para sustentar las políticas $y$ las reformas. Un fuerte sistema de conocimiento combina datos descriptivos de sistemas, hallazgos de investigación y conocimiento de los practicantes. La clave es conocer qué usar, por qué y cómo.

Crear sistemas de gobernanza abiertos, dinámicos y estratégicos necesarios para dirigir sistemas complejos no es fácil. La gobernanza moderna debe ser capaz de combinar el dinamismo y la complejidad y a la vez mantener claramente el rumbo hacia objetivos establecidos. $\mathrm{Y}$ con recursos financieros limitados debe hacerlo con la mayor eficiencia posible. Si bien se trata de una tarea difícil, es necesaria.

\section{Enlaces útiles}

El artículo original sobre Esenciales OCDE, incluidos enlaces y material complementario, puede consultarse en: $h t t p: / / w p \cdot m e / p 2 v 60 D-2 D 9$

Consulte la serie completa en: http://oecdinsights.org/?s=NAEC+complexity 


\section{El desarrollo como resultado de un sistema adaptativo complejo}

por Frans Lammersen y Jorge Moreira da Silva (Director), Dirección de la Cooperación al Desarrollo de la OCDE - DCD-DAC

En La riqueza de las naciones, Adam Smith dijo: "Poco más se requiere para llevar un Estado a su grado más alto de opulencia desde la barbarie más rastrera, salvo la paz, los impuestos cómodos y una tolerable administración de justicia; todo lo demás resulta como consecuencia del curso natural de las cosas". Otros fueron menos optimistas. Afirmaron que las naciones son ricas o pobres debido a sus diferencias en religión, cultura, patrimonio y/o geografía.

Las teorías modernas de desarrollo económico tuvieron su origen en las ideas sobre la reconstrucción de Europa en el periodo posterior a la Segunda Guerra Mundial. El Programa de Recuperación Europea, o Plan Marshall, se basó en el concepto de que el crecimiento económico puede ser reprimido por las instituciones locales y las actitudes sociales, en especial si estas influyen en la tasa de ahorro interno y de inversión. De acuerdo con este modelo lineal de crecimiento, una inyección masiva y correctamente diseñada de capital, combinada con la intervención del sector público para resolver deficiencias del mercado, al final conducirían a la industrialización y el desarrollo económico. Desde entonces se han enunciado muchas otras teorías sobre el desarrollo económico, pero ninguna ha logrado explicar, de manera convincente, por qué algunos países viven un crecimiento económico rápido y otros no.

La comunidad del desarrollo ha seguido su búsqueda del ingrediente que falta para provocar el crecimiento económico.Algunos candidatos han sido el capital, la tecnología, las políticas públicas, las instituciones, una mejor política y la integración del mercado. Cada vez que pensamos que hemos identificado eso que falta, nos damos cuenta de que, de hecho, no es algo que pueda proporcionarse desde afuera, sino que es una característica endógena del propio sistema. Tradicionalmente, la ayuda al desarrollo se ha basado en una mentalidad relacionada con la ingeniería, la producción masiva y las bandas transportadoras, en que los organismos ofrecen soluciones mágicas para problemas tan complejos como la erradicación 
del paludismo, la reducción de la vulnerabilidad, la mejora de la resiliencia, el fortalecimiento de la conectividad, entre otros. Por desgracia, los programas de desarrollo fragmentados o de avance gradual a menudo no han cumplido su objetivo.

Cada vez más, el pensamiento de la complejidad —una manera de entender cómo los elementos de los sistemas interactúan y cambian con el tiempo- logró integrarse en el discurso del desarrollo. Después de todo, ¿qué podría ser más complejo que fomentar el desarrollo, la sostenibilidad, los derechos humanos, la paz y la gobernanza? Deberíamos pensar en que la economía y la sociedad están compuestas por un rico conjunto de interacciones entre grandes números de agentes adaptativos, todos los cuales coevolucionan. Con base en este enfoque, el desarrollo no es solamente un aumento en los productos, sino también el surgimiento de un sistema entrelazado de instituciones, empresas, productos y tecnologías económicos, financieros, legales, sociales y políticos. Juntos, estos elementos y su interacción ofrecen a los ciudadanos la capacidad de tener una vida feliz, saludable y satisfactoria.

Una vez que contemplamos el desarrollo como el resultado de un sistema adaptativo complejo y no como la suma de lo que le sucede a las personas y a las empresas, obtendremos mejores perspectivas de cómo podemos ayudar a acelerar y conformar el desarrollo. Seríamos más eficaces si evaluamos los retos del desarrollo a través de este prisma de sistemas adaptativos complejos. Esto podría arrojar perspectivas importantes sobre cómo priorizar, diseñar y cumplir mejor programas integrales de desarrollo, con miras a lograr los múltiples objetivos de inclusión, sostenibilidad y crecimiento económico que sustentan la Agenda 2030 para el Desarrollo Sostenible. Las agencias de ayuda al desarrollo apoyan cada vez más la idea de que las soluciones a problemas complejos deben evolucionar, mediante ensayo y error, y que los programas exitosos probablemente sean diferentes para cada contexto local, con su historia, sus recursos y sus redes de relaciones sociales particulares. La clave para toda persona involucrada en la ayuda al desarrollo es dejar de lado sus propias ideas preconcebidas y dedicarse primero a observar, detectar y escuchar con atención para identificar las áreas en las que ya está sucediendo un cambio para mejorar y después intentar alentar y nutrir aún más ese cambio. 
La complejidad tiene importancia, sobre todo cuando el conocimiento y las capacidades requeridos para solucionar los problemas están repartidos entre los actores sin vínculos institucionales fuertes y formales. Intrínsecos a muchos problemas complejos son los intereses divergentes, los objetivos en conflicto o las narrativas contrapuestas. Más aún, a menudo no queda claro cómo lograr un objetivo determinado en un contexto específico, o cambiar procesos que implican fuerzas significativas e impredecibles. Al mismo tiempo, es importante hacer hincapié en que el consejo relativo a la complejidad no deberá tomarse como un consejo de resignación respecto al desarrollo. Ha habido un inmenso progreso social y económico y la ayuda al desarrollo ha demostrado ser útil en general. La cooperación para el desarrollo ha contribuido a lograr los objetivos económicos al ayudar a los países en desarrollo a conectar a sus empresas con los mercados internacionales; a alcanzar objetivos sociales al hacer que la globalización propicie un beneficio para los pobres y la reducción de la desigualdad, y lograr los objetivos ambientales al adaptarse al cambio climático y a la vez explotar las ventajas comparativas.

Sin embargo, no todos los retos del desarrollo son complejos por naturaleza. En el caso de los que sí lo sean, la complejidad no deberá utilizarse como excusa para el fatalismo y la inercia. Más bien deberíamos esforzarnos por promover la innovación, la experimentación y la renovación. Deberíamos forjar alianzas para aprender del pasado, lo que nos permitirá configurar enfoques que tengan mayores probabilidades de funcionar y que sean aceptados por las personas a quienes intentamos ayudar. Ellos nos dirán qué funciona y qué no. En conjunto podemos construir una narrativa para el cambio que involucre muchas voces y perspectivas diferentes. También debemos ser moderados y darnos cuenta de que podría ser mejor empezar con poco y aprender y adaptarnos a medida que avanzamos en procesos de diálogo reiterativos. Debemos seguir buscando el cambio, explorando con amplitud para encontrar nuevos factores que surjan en el mundo global; escuchar diversas opiniones para tener mayor capacidad de anticiparnos y adaptarnos y aprovechar las oportunidades. 
Aceptar la complejidad cuando es importante hacerlo nos permitirá contribuir con mayor eficacia a la Agenda 2030 para el Desarrollo Sostenible.

\section{Enlaces útiles}

El artículo original sobre Esenciales OCDE, incluidos enlaces y material complementario, puede consultarse en: $h t t p: / / w p . m e / p 2 v 60 D-2 M L$ Consulte la serie completa en: http://oecdinsights.org/?s=NAEC+complexity 
Hacia una nueva narrativa 


\section{Cantar para nuestro tiempo también, o lo que Homero puede enseñarnos sobre la complejidad}

por Patrick Love, Dirección de Asuntos Públicos y Comunicaciones de la OCDE

En el Seminario sobre Complejidad y Políticas Públicas organizado por el equipo de Nuevos Enfoques ante los Retos Económicos (NAEC, por sus siglas en inglés) de la OCDE, junto con la Comisión Europea y el Institute for New Economic Thinking (INET), se incluyó un debate sobre la manera de construir una narrativa en torno a la complejidad. Según señaló un participante, la "economía de la complejidad" no es el título más estimulante, excepto (quizá) para los economistas de la complejidad. Pero "narrativa" fue uno de los términos clave en los debates, junto con la complejidad de "navegar" o sortear escollos. Si añadimos a esto la petición de modestia planteada por Lex Hoogduin en su artículo para los Esenciales y durante el debate, pensamos que podríamos aprender algo de un experto en narrativa, navegación y modestia: Homero.

La Ilíada y la Odisea comienzan con peticiones semejantes a la Musa de que narre la historia del héroe, aunque con una asombrosa excepción. En la Ilíada, se le pide que hable de la ira de Aquiles y la épica que sigue a continuación es un relato más o menos cronológico de 10 días al final de la Guerra de Troya. Por otra parte, en la Odisea el poeta sugiere que la diosa empiece la narración donde considere mejor. Una razón podría ser que, en nuestros términos, la Ilíada es una narración lineal, en la que un suceso ocasiona y conduce al siguiente, en tanto que la Odisea es compleja y salta de un sitio a otro en el espacio y el tiempo, y los eventos separados se influyen mutuamente, a menudo en maneras involuntarias.

El punto en el que usted empieza una narrativa compleja determina lo que describe y, hasta cierto grado, cómo lo describe. Si, por ejemplo, empieza con su explicación de la crisis financiera con el colapso de Lehmann Brothers, contará la historia de una manera. Si empieza unos años atrás, con la desregulación del mercado, la historia será diferente. Regrese al final de la responsabilidad ilimitada de los actores y esto abre la posibilidad a otra trama y conjunto de personajes. Donde fuera que decidiera empezar, contaría la historia 
verdadera, pero no la única historia. Así que, al contar una historia compleja, tiene que decidir primero lo que desea que la audiencia recuerde, y después decide qué combinación de los ilimitados elementos disponibles les permitiría entender mejor los temas y llegar a un acuerdo sobre un curso de acción a seguir.

Otra lección que podemos aprender de Homero es que en una narración no compleja puede haber una "visión del ojo de Dios" de la narrativa, como cuando Aquiles contempla el escudo que para él hizo el dios Efesto. En la Odisea, el narrador no sabe esto y es, de hecho, parte de la historia él mismo e influye en su desenlace. Eric Beinhocker del INET, quien coorganizó el seminario de Complejidad NAEC, relaciona esto con los teoremas de incompletitud de Gödel, afirmando que podría resultar imposible para un agente incorporado en el sistema acceder a información que un agente ajeno al sistema con una visión del ojo de Dios tendría.

Una vez que usted decide lo que desea decir y selecciona lo que utilizará para decirlo, queda la pregunta de cómo decirlo. Los expertos en políticas públicas, al igual que los de otros campos, suelen defender su comunicación deficiente explicando que el tema es complicado y que no debería simplificarse. El siguiente es un extracto de la crítica de Einstein de la cosmología newtoniana contenida en Sobre la Teoría de la Relatividad Especial y General: "Si reflexionamos sobre la pregunta de cómo debe contemplarse el universo, considerado como un todo, la primera respuesta que viene a la mente con seguridad es: Con respecto al espacio (y el tiempo), el universo es infinito. Hay estrellas en todas partes, de modo que la densidad de la materia, aunque muy variable en detalle, es no obstante en promedio la misma en todas partes. En otras palabras: Por muy lejos que pudiéramos viajar a través del espacio, deberíamos encontrar por doquier un atenuado enjambre de estrellas fijas de aproximadamente el mismo tipo y densidad".

Prácticamente cualquier adulto o joven que sepa leer es capaz de entender lo que quiso decir Einstein, por complicado que sea el tema. A manera de comparación, la siguiente es la explicación de la OCDE de un concepto fundamental de economía: “...las diferencias relativas de costo que definen la ventaja comparativa y son la fuente del comercio, desaparecen una vez que se logra el equilibrio con el 
libre comercio. Esto es, los dos países que aparecen en la balanza comercial de la Gráfica 1.2 operan en puntos de sus Fronteras de Posibilidad de Producción (FPP) en los que la inclinación es igual al precio relativo mundial común. Por consiguiente, no es posible observar la ventaja comparativa en una balanza de libre comercio, a partir de costos marginales relativos". ¿Puede usted deducir con esta manifestación si estamos a favor o en contra del libre comercio?

Resulta asombroso que en tantos ámbitos los mayores expertos sean los más fuertes defensores de la sencillez. David Hilbert estableció la agenda de las matemáticas del siglo XX en el Congreso Internacional de Matemáticos de París 1900, en un documento sobre 23 problemas no resueltos. Hilbert afirmó lo siguiente: "Una teoría matemática no puede considerarse completa mientras no la hayas dejado tan clara que puedas explicársela a la primera persona con quien te encuentres en la calle". El genio de las matemáticas Alan Turing fue aún más atrevido al declarar que "Ningún método matemático puede ser útil para ningún problema si implica hacer muchos cálculos". (Turing escribió un documento sobre la teoría de la computabilidad sin utilizar ecuaciones, basando su explicación en acertijos vendidos en las jugueterías.)

Hay una última lección que podemos tomar de Homero con el carácter de sus héroes. Aquiles es arrogante, inmaduro, impulsivo y egocéntrico ("el Mejor de los Aqueos", lo cual nos hace preguntarnos cómo eran los demás). Es fuerte y es bueno para matar gente, pero acaba muerto. Ulises es listo y es bueno para persuadir a otros. Es modesto y escucha los consejos. Se preocupa por los demás. Y logra navegar de regreso a Ítaca y a Penélope. En un mundo complejo, hoy o como el que describió Homero, se logrará más con estrategia e ingenio que con la fuerza bruta. El poeta no solo le pide a la diosa que "empiece desde donde quiera", sino que "cante para nuestro tiempo también".

\section{Enlaces útiles}

El artículo original sobre Esenciales OCDE, incluidos enlaces y material complementario, puede consultarse en: http://wp.me/p2u6oD-2Ed

Consulte la serie completa en: http://oecdinsights.org/?s=NAEC+complexity 


\section{Una nueva narrativa para una era compleja}

por Eric Beinhocker, Director Ejecutivo, The Institute for New Economic Thinking at the Oxford Martin School

Si 2008 fue el año de la crisis financiera, 2016 fue el año de la quiebra política. En ese año fuimos testigos del colapso de la última de las cuatro grandes ideologías económico-políticas que predominaron en el siglo XX: el nacionalismo, el pragmatismo keynesiano, el socialismo y el neoliberalismo. En las décadas de 1970 y de 1980 en muchos países la centro derecha abandonó el keynesianismo y adoptó el neoliberalismo. En las décadas de 1980 y 1990 siguió la centro izquierda, que en gran medida abandonó el socialismo democrático y adoptó una versión más suave del neoliberalismo.

Durante algunas décadas pensamos que había llegado el final de historia y que las batallas políticas en la mayoría de los países de la OCDE se libraban entre los partidos de centro izquierda y centro derecha, los cuales debatían en un estrecho espectro político, pero en gran medida estaban de acuerdo en temas como el libre comercio, los beneficios de la inmigración, la necesidad de tener mercados eficientes y flexibles y el papel positivo de las finanzas mundiales. Este consenso lo reforzaron instituciones internacionales como el Fondo Monetario Internacional (FMI), el Banco Mundial y la OCDE, así como la elite política y empresarial de Davos.

En 2008 dicho consenso resultó sacudido y el año pasado, desmoronado. Algunos se aferrarán a la idea de que podrá revivírsele. Dirán que lo único que necesitamos es defenderlo con mayor vigor, que los hechos acabarán por prevalecer, que los populistas exageran, que en realidad solo tiene que ver con la migración, que el Brexit será cuestión de avenencia, que Clinton obtuvo más votos que Trump, y así sucesivamente. Pero esto es una ilusión. Grandes sectores del electorado han perdido la fe en el consenso neoliberal, en los partidos políticos que lo apoyaron y en las instituciones que lo promovieron. Esto creó un vacío ideológico que se llenó de ideas viejas y malas, sobre todo de un renacimiento del nacionalismo en Estados Unidos y en varios países europeos, así como un renacimiento de la izquierda socialista dura en algunos países. 
La historia nos muestra que las oleadas populistas pueden causar desastres o reformas. Ciertamente, el desastre es un escenario realista ahora, con una posible desintegración de la cooperación internacional, el conflicto geopolítico y muy malas políticas económicas. Pero también podemos considerar la historia y ver cómo, por ejemplo, en Estados Unidos, a principios del siglo XX, Teddy Roosevelt aprovechó el descontento populista para crear un periodo de grandes reformas y progreso.

Entonces, ¿cómo inclinamos la balanza del desastre a la reforma? En primer lugar, escuchando. En los movimientos populistas sí participan algunas personas racistas, xenófobas y auténticamente dementes, y otras a quienes absolutamente deberíamos condenar. Pero también cuentan con muchas personas normales a quienes se alimenta con un sistema que no siempre funciona para ellas. Quienes han visto que su nivel de vida se estanca o baja, que viven precariamente con un cheque por su sueldo a la vez, que piensan que el destino de sus hijos será peor que el propio. Y los problemas no son únicamente económicos, también son sociales y psicológicos. Han perdido dignidad y respeto y anhelan un sentido de identidad y pertenencia.

Sienten, de manera correcta o incorrecta, que han seguido las reglas, pero otros miembros de la sociedad no lo han hecho y que se ha recompensado a esos otros. También sienten que sus líderes e instituciones políticos están profundamente alejados de la realidad, no son confiables y actúan para su propio beneficio. Y, por último, se sienten a merced de grandes fuerzas impersonales: la globalización, el cambio tecnológico, bancos desarraigados y grandes corporaciones sin rostro. El lema populista más eficaz ha sido "recuperar el control".

Tras escuchar, tenemos después que dar nuevas respuestas. Nuevas narrativas y políticas acerca de cómo puede mejorarse y volverse más segura la vida de las personas, cómo pueden gozar con justicia de una parte de la prosperidad de su país, cómo pueden tener más control sobre su vida, cómo pueden vivir con dignidad y respeto, cómo actuarán todos siguiendo las mismas reglas y el contrato social se restituirá, cómo la apertura y la cooperación internacional los beneficia a ellos y no únicamente a una elite, y cómo los gobiernos, las corporaciones y la banca servirán a sus intereses y no lo contrario. 
Para eso necesitamos un nuevo pensamiento económico. Por eso es tan importante la iniciativa NAEC. La OCDE ha tomado en serio la desigualdad y el estancamiento económicos durante más tiempo que la mayoría, y tiene algunos de los mejores datos y análisis de estos problemas. Ha hecho un trabajo de vanguardia en parámetros alternativos al PIB para obtener una perspectiva de cómo les va en realidad a las personas en cuanto a bienestar. Trabaja arduamente para articular nuevos modelos de crecimiento que sean incluyentes y ambientalmente sostenibles. Tiene iniciativas destacadas en educación, salud, ciudades, productividad, comercio y muchos otros temas que resultan imprescindibles para una nueva narrativa.

Pero también hay brechas. Los modelos económicos racionales ayudan poco respecto a estos asuntos y se requiere un conocimiento más profundo de psicología, sociología, ciencias políticas, antropología e historia. De igual manera, la comunicación es fundamental: los informes de un largo número de páginas son importantes para los ministerios gubernamentales, pero para cambiar el pensamiento de los medios y del público se necesitan historias, narrativas, materiales visuales y memes.

Entonces, ¿cómo podría ser una nueva narrativa? Tengo la esperanza de que, incluso en esta era de la posverdad, esta se basará en los mejores hechos y en los mejores conocimientos científicos disponibles. Creo que contendrá cuatro historias:

$>$ Una nueva historia de crecimiento

> Una nueva historia de inclusión

$>$ Un nuevo contrato social

$>$ Un nuevo idealismo

Este último punto no se debate lo suficiente. Los periodos de progreso suelen caracterizarse por el idealismo, los proyectos comunes a los que todos podemos aspirar. El populismo es una mentalidad de suma cero: el líder populista me ayudará a obtener una rebanada más grande de un pastel determinado. El idealismo es una mentalidad de suma positiva: podemos hacer grandes cosas juntos. El idealismo es el antídoto más potente para el populismo. 
La economía se ha descrito a sí misma como una ciencia amoral separada, pero los seres humanos somos criaturas morales. Debemos devolver la moralidad al centro de la economía para que las personas se relacionen con ella y confíen en ella. Algunos quizá cuestionen si este es un territorio en el que la OCDE debería intervenir. Pero la Organización se fundó "para mejorar el bienestar social y económico de todos los pueblos del mundo" y para ofrecer un foro donde los gobiernos "buscan soluciones a los problemas comunes". Estos problemas afectarán dramáticamente el bienestar de los habitantes de todo el mundo en las décadas futuras y ciertamente son comunes.

Por tal razón, espero que la OCDE siga desempeñando un papel de liderazgo, mediante la NAEC y sus demás iniciativas, sobre el nuevo pensamiento económico, no solo en un sentido técnico estrecho, sino también en el sentido amplio de ayudar a forjar una nueva visión que coloque a la gente de nuevo como elemento central de nuestra economía. Nos encontramos ciertamente en un punto fluido de la historia. Podría representar un gran paso hacia atrás o un gran paso hacia delante y todos debemos empujar juntos hacia adelante.

\section{Enlaces útiles}

El artículo original sobre Esenciales OCDE, incluidos enlaces y material complementario, puede consultarse en: http://wp.me/p2v6oD-2Nl

Consulte la serie completa en: http://oecdinsights.org/?s=NAEC+complexity 


\section{Decir toda la verdad en un entorno de posverdad}

por Gabriela Ramos, Directora de Gabinete de la OCDE y Sherpa ante el G20

En 2016, de manera sorpresiva para muchos, Oxford Dictionaries eligió "posverdad" como su Palabra del Año; el adjetivo se define como sigue: "relacionado con o que denota circunstancias en las que los hechos objetivos influyen menos en conformar la opinión pública que los llamados a la emoción y las creencias personales". Esto se opone al precepto principal de la OCDE, la "casa de las mejores prácticas", cuyos trabajos y análisis dependen de estadísticas de alta calidad y de una sólida evidencia empírica. De modo que ¿cómo llegamos aquí y qué significa esto para nuestras democracias?

Como Sherpa de la OCDE ante el G20, he sido testigo de la evolución de lo que originalmente fue una crisis financiera en una crisis económica y, en fecha más reciente, después de ocho años de bajo crecimiento y una muy lenta recuperación, en una crisis política definida por la falta de confianza de la gente en las instituciones que hemos construido a lo largo de tantas décadas. También resulta claro que los valores de apertura, asistencia mutua e integración internacional sobre los cuales se asienta la OCDE están siendo cuestionados.

Una razón de ello es que, si bien hemos dicho "la verdad y nada más que la verdad", no hemos dicho "toda la verdad". Al igual que las personas que se aíslan en silos mediáticos que únicamente les comunican noticias y opiniones con las que se sienten cómodas, nos ha complacido basarnos en modelos económicos que trabajan con datos reconfortantemente cuantitativos sobre PIB, ingreso per cápita, flujos comerciales, asignación de recursos, productividad, entre otros. Dichos modelos económicos estándar no anticiparon el nivel de descontento creado por los sesgados resultados que alcanzaban y que ha prevalecido por tantos años.

Nuestras "verdades" no reflejaron dimensiones muy relevantes que sustentan las decisiones de la gente (incluso las decisiones políticas recientes), en particular las que son conceptos intangibles 
o no mensurables. Por tal razón asuntos de tanta importancia como la justicia, la confianza o la cohesión social simplemente se ignoraron en los modelos. De hecho, la economía neoliberal nos enseñó que las personas son racionales y que siempre tomarán las mejores decisiones de acuerdo con la información que tienen para maximizar los servicios públicos. Y esa acumulación de decisiones racionales aportará los mejores resultados en su conjunto. En este modelo no hay cabida para las emociones o para conceptos como la justicia o el resentimiento.

El populismo, el contragolpe a la globalización —puede llamársele como se quiera- reconoce estas emociones. Nosotros también deberíamos hacerlo, en especial porque de hecho tenemos los datos y los hechos que originaron estos sentimientos en primer lugar. Me refiero a la creciente desigualdad del ingreso y los resultados que casi todas las economías de la OCDE experimentaron aun antes de la crisis y que la crisis empeoró.

Si dejamos atrás los promedios y el PIB per cápita y observamos, por ejemplo, el impacto distributivo de nuestras decisiones económicas, el panorama es devastador. Para hasta $49 \%$ de la población ubicada en el 10\% más bajo de la distribución de ingresos en los países de la OCDE (y $60 \%$ en mi país, México), la situación no ha mejorado en las últimas décadas. Además, los grupos de bajos ingresos acumulan desventajas, pues su condición inicial no les permite acceder a educación y servicios de salud de calidad o a empleos satisfactorios, en tanto que sus hijos afrontan un futuro sombrío con menos oportunidades de mejorar su destino. En la OCDE lo hemos confirmado. Según nuestros datos, si uno nace en una familia cuyos padres no llegaron al nivel de educación superior, tiene cuatro menos oportunidades de llegar a la escuela media superior. Quizá sufra más problemas de salud y tenga empleos menos satisfactorios y sueldos más bajos. Se encuentra atrapado en un círculo vicioso de carencias.

Incluso las vagamente definidas clases medias de los países de la OCDE tienen temor por su futuro y el de sus hijos. También se sienten traicionadas y molestas porque, pese a trabajar arduamente, ahorrar y hacer todo lo demás que supuestamente garantiza una buena vida, ven que los frutos del éxito son recogidos por una elite 
minúscula, mientras que ellos se quedan atrás. No es de extrañar que se sientan atraídos por soluciones que concuerdan con sus emociones y parecen darles algo de esperanza.

¿Qué debería hacer en este contexto una organización como la OCDE, comprometida con el asesoramiento sobre políticas públicas con base en evidencias? En primer lugar, debemos alzar la voz cuando se tergiversan de manera deliberada los hechos y las realidades. Aun si las personas que dicen estas mentiras no están conscientes de ello, eso no las exime de la responsabilidad de verificar la evidencia. Presentar una visión basada en mentiras por omisión o adrede deberá reconocerse como tal y no deberá quedar sin respuesta en el entorno de la "posverdad".

En segundo lugar, en vez de defender nuestra selección de los hechos, debemos reconocer que también estos estaban sesgados y que en muchos casos representaban ideas preconcebidas de cómo funciona la economía que se ha comprobado que están equivocadas. Para reconstruir la confianza en los hechos que generamos para explicar los fenómenos sociales y económicos, tendremos que cerciorarnos de que representan la realidad completa y ofrezcan soluciones funcionales. Quizá debamos empezar, como mencionó la Estadística en Jefe de la OCDE: "por medir lo que atesoramos y no atesorar lo que medimos".

La mayoría de nosotros tenemos que comprender que los retos económicos no son solo económicos. Por ello la iniciativa Nuevos Enfoques ante los Retos Económicos (NAEC, por sus siglas en inglés) de la OCDE promueve una visión multidimensional del bienestar de las personas, con elementos tangibles e intangibles (incluyendo emociones y percepciones), todos dignos de consideración. La agenda NAEC es ambiciosa; requiere una nueva narrativa de crecimiento que reconozca la complejidad del comportamiento humano y de las instituciones, y apele a la sociología, la psicología, la biología, la historia y otras disciplinas a ayudar a escribir esta narrativa y construir mejores modelos que sustenten las decisiones económicas.

Pensamos que solo había una verdad y la promovimos sin considerar que podría haber tenido fallas. Definimos la realidad de ciertas maneras e ignoramos las críticas a los modelos. Creímos 
de manera firme, y errónea, que los mercados eran la respuesta absoluta.

Pienso que como economistas y responsables de formular políticas públicas, deberíamos recordar que en La riqueza de las naciones, Adam Smith sacó conclusiones no solamente de la metodología, sino también de la ética y la psicología que exploró en La teoría de los sentimientos morales. Quizá tengamos que enriquecer nuestros modelos para garantizar que los resultados respondan a las expectativas de las personas y nos ayuden a recuperar el componente más importante de nuestra sociedad: la confianza.

\section{Enlaces útiles}

El artículo original sobre Esenciales OCDE, incluidos enlaces y material complementario, puede consultarse en: http://wp.me/p2u6oD-2NH

Consulte la serie completa en: http://oecdinsights.org/?s=NAEC+complexity 


\section{ESENCIALES OCDE}

\section{Complejidad y formulación de políticas públicas}

Análisis de temas La iniciativa Nuevos Enfoques ante los Retos de actualidad Económicos de la OCDE invitó a los expertos internos y externos de la organización a analizar la teoría de la complejidad como un medio para comprender mejor la naturaleza interconectada de las tendencias y las influencias que conforman nuestro entorno socioeconómico. Sus aportaciones, aquí reunidas, examinan los supuestos, las fortalezas y las deficiencias de los modelos tradicionales, y proponen una manera de construir nuevos modelos que tomen en cuenta factores como la psicología, la historia y la cultura, descuidados por estos modelos. Los autores se centran en la disciplina de la economía como tal, el sistema financiero y las aplicaciones de la teoría de la complejidad a la formulación de políticas y la gobernanza. Sostienen que se requiere una nueva narrativa que integre las esperanzas, los valores, las actitudes y las conductas de las personas en la economía, junto con los hechos y los datos que los economistas están más acostumbrados a tratar.

Otros títulos de esta colección son:

Desigualdad de ingresos. La brecha entre ricos y pobres Inversión. Análisis de temas de actualidad Envejecimiento. Análisis de temas de actualidad Nuevos enfoques ante los retos económicos. Análisis de temas de actualidad

Visite el sitio de las obras en inglés: www.oecd.org/insights Asimismo, el blog de la colección Insights en inglés: www.oecdinsights.org

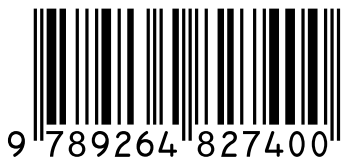

